3-3-2020

\title{
Contraceptive use dynamics in India: A prospective cohort study of modern reversible contraceptive users
}

Arupendra Mozumdar

Population Council

Elizabeth Tobey

Population Council

Kumudha Aruldas

Rajib Acharya

Population Council

Aparna Jain

Population Council

Follow this and additional works at: https://knowledgecommons.popcouncil.org/departments_sbsr-rh

Part of the Demography, Population, and Ecology Commons, and the International Public Health Commons

How does access to this work benefit you? Let us know!

\section{Recommended Citation}

Mozumdar, Arupendra, Elizabeth Tobey, Kumudha Aruldas, Rajib Acharya, and Aparna Jain. 2020.

"Contraceptive use dynamics in India: A prospective cohort study of modern reversible contraceptive users," Research report. Washington, DC: Population Council, The Evidence Project. 


\section{Contraceptive use dynamics in India:}

A prospective cohort study of modern reversible contraceptive users

Arupendra Mozumdar, Population Council, New Delhi, India

Elizabeth Tobey, Population Council, Washington, DC

Kumudha Aruldas, Christian Medical College, Vellore, India

Rajib Acharya, Population Council, New Delhi, India

0

Aparna Jain, Population Council, Washington, DC

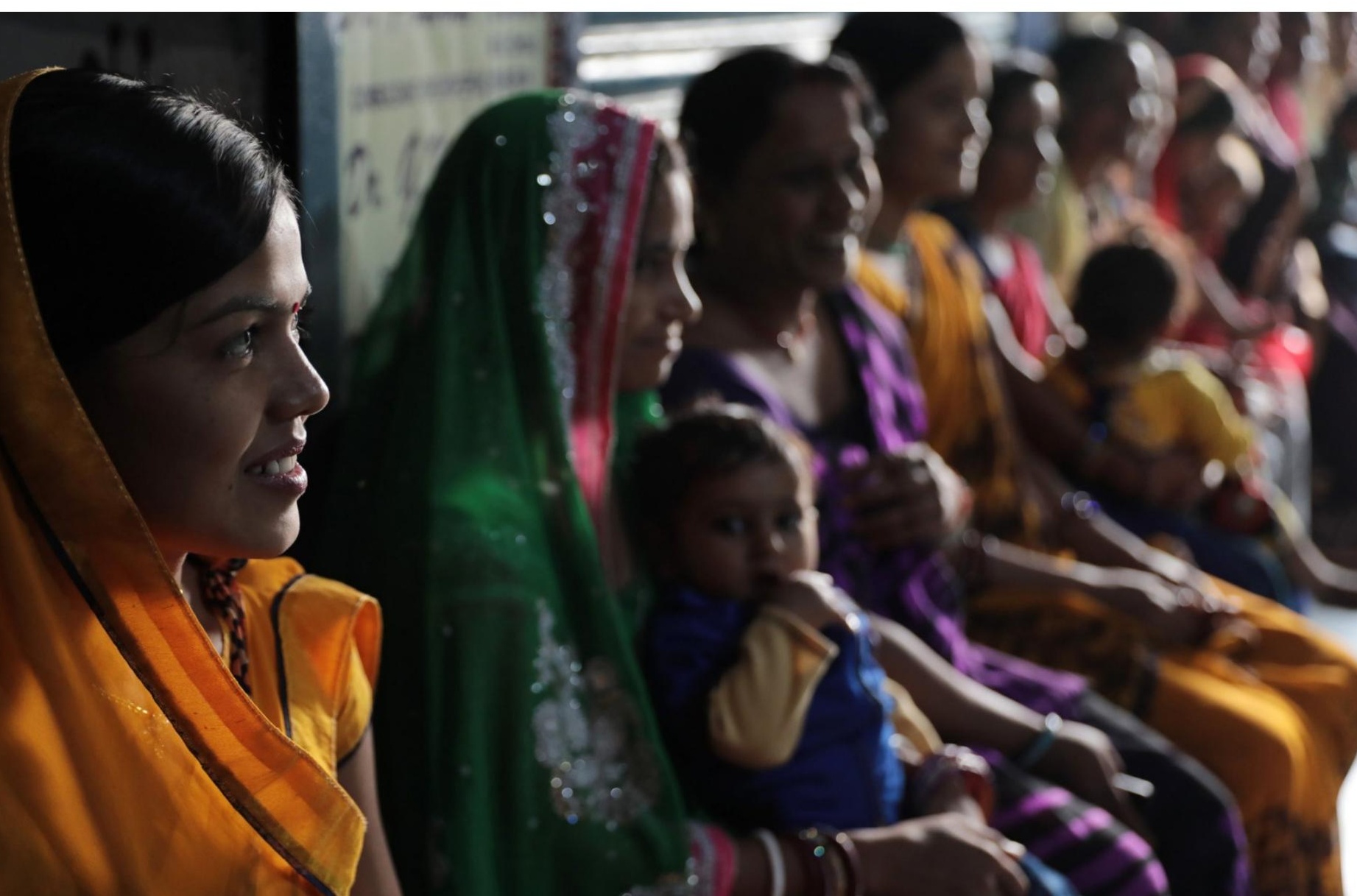




\section{The Evidence Project}

Population Council

4301 Connecticut Avenue, NW, Suite 280

Washington, DC 20008 USA

tel +12022379400

evidenceproject.popcouncil.org

The Evidence Project is made possible by the generous support of the American people through the United States Agency for International Development (USAID) under the terms of cooperative agreement no. AID-OAA-A-13-00087.

The contents of this document are the sole responsibility of the Evidence Project and Population Council and do not necessarily reflect the views of USAID or the United States Government.

Evidence Project is led by the Population Council.

Published in March 2020.

Suggested citation: Mozumdar, Arupendra, Elizabeth Tobey, Kumudha Aruldas, Rajib Acharya, and Aparna Jain. 2020. "Contraceptive use dynamics in India: A prospective cohort study of modern reversible contraceptive users," Research Report. Washington, DC: Population Council, The Evidence Project.

Photo credit on cover page: Paula Bronsten/The Verbatim Agency/Getty Images.

(C) 2020, The Population Council, Inc. 



\section{Table of Contents}

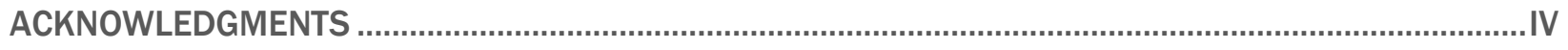

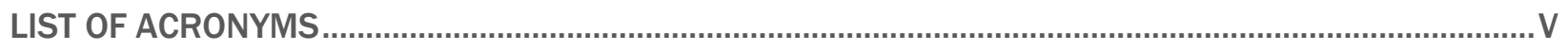

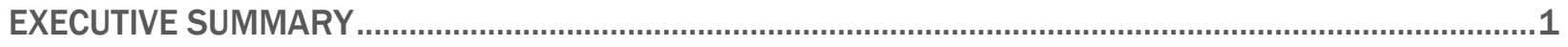

INTRODUCTION

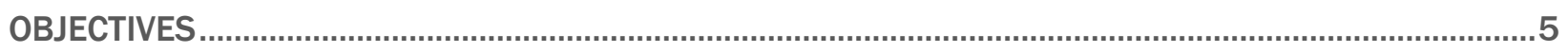

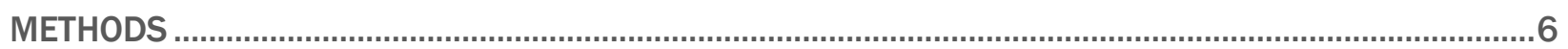

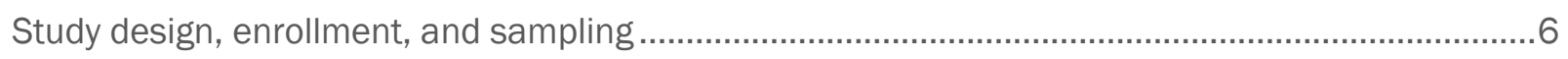

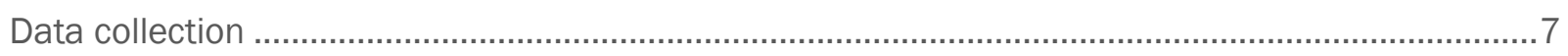

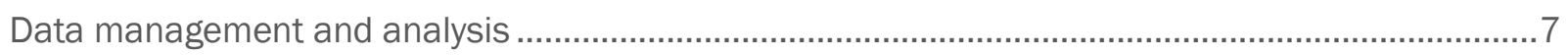

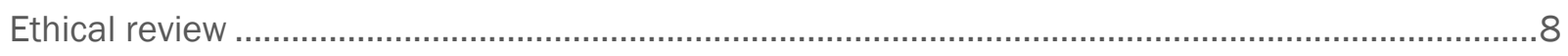

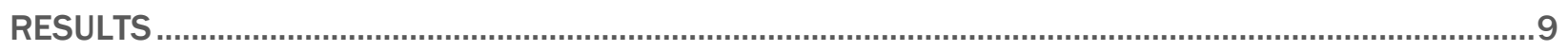

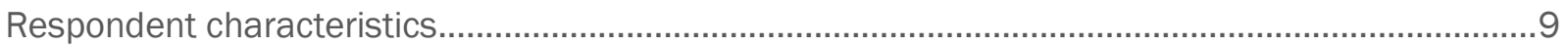

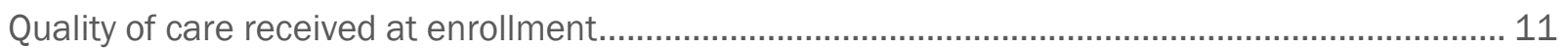

Experiences of side effects on enrollment method ...................................................................... 17

Reasons for discontinuation of enrollment method ....................................................................... 19

Contraceptive use dynamics after 12 months ............................................................................ 21

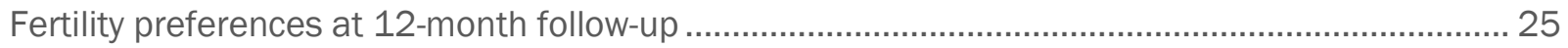

Experiences using and obtaining contraceptive methods at 12 months ....................................... 27

Experiences of pregnancy during 12-month study period............................................................ 31

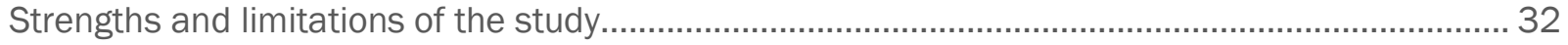

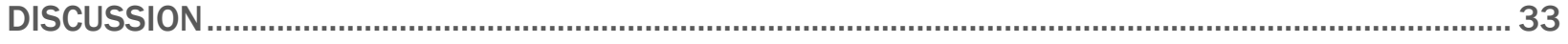

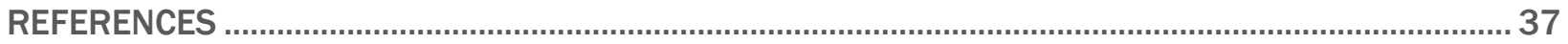




\section{List of Figures}

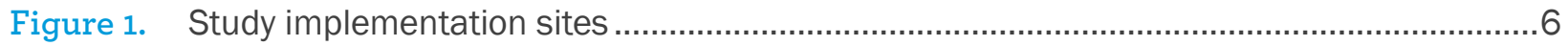

Figure 2. Respectful care at initial visit by enrollment method....................................................... 11

Figure 3. Method selection at initial visit by enrollment method .................................................. 12

Figure 4. Effective use of selected method at initial visit by enrollment method.......................... 13

Figure 5. Continuity of contraceptive use and care at initial visit by enrollment method ................ 14

Figure 6. Receipt of complete information on the Mllplus at enrollment, by method and

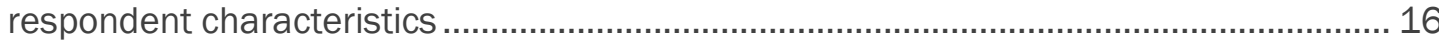

Figure 7. Women's movement through various contraceptive use states over 1-year study

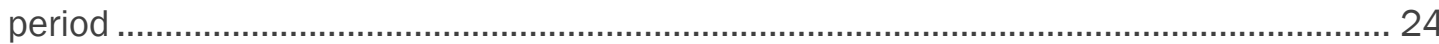

Figure 8. Fertility preferences at 12-month follow-up among users of modern methods, traditional methods, and those not using any method ..................................................... 25

Figure 9. Individual women's changes in fertility preferences over 1-year study period ................. 26

Figure 10. Source of most recent OCP packet among OCP users at 12-month follow-up $(n=848) \ldots 27$

\section{List of Tables}

Table 1. Proportion of enrolled respondents interviewed at each time-point, by enrollment

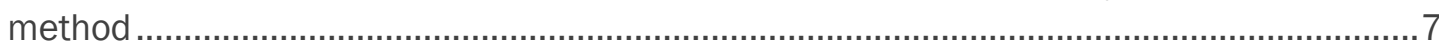

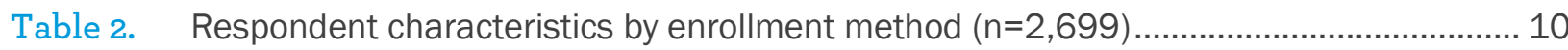

Table 3. Experiences of side effects on enrollment method, by enrollment method..................... 17

Table 4. Reactions to side effects of enrollment method among women who experienced side effects, by enrollment method...................................................................................... 18

Table 5. Reasons for discontinuation of enrollment method, by enrollment method.................... 20

Table 6. Contraceptive use at 12-month interview, by enrollment method................................. 22

Table 7. Among OCP users at 12-months, the percentage who missed a dose and their

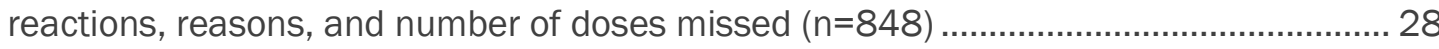

Table 8. Proportion of IUD users who went for IUD follow-up visit, location of visit and person

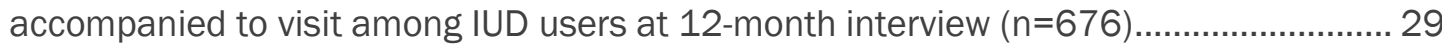

Table 9. Details of female sterilization adoption by 12-month follow-up interview $(n=41) \ldots \ldots \ldots . . . .30$

Table 10. Experience of pregnancy during the 12-month study period, by enrollment method....... 31

Table 11. Intendedness of pregnancy when first reported, among women who experienced a pregnancy during the study period, by enrollment method 


\section{Acknowledgments}

The authors wish to acknowledge many individuals and institutions for their contributions. We acknowledge the generous support of the USAID Mission in India for making this study possible, in particular, Subrato Mondal and Amit Shah. We also acknowledge the Governments of Odisha and Haryana as well as the administrative authorities of Baleswar, Bhadrak, Kendujhar, Khorda, and Mayurbhanj districts of Odisha and Nuh, Panipat, Sonipat, and Rewari districts of Haryana for their support in this study. Special thanks are due to the study coordinators and data collectors for ensuring the quality of data collection, as well as to the Accredited Social Health Activists (ASHAs) for aiding with enrollment of women into the study.

We acknowledge the individuals who provided inputs into the study design and implementation, including Mihira Karra and Erika Martin from USAID Washington, DC. We acknowledge colleagues at the Population Council, including Niranjan Saggurti, India Country Director, for his guidance in the study implementation and review of this report; Aastha Kant, formerly of Population Council, for her support with study implementation; and Michelle Hindin, Reproductive Health Program Director and Director of the Evidence Project, for her review of the report.

We are also thankful for the Study Advisory Committee, who provided helpful input in the early stages of this study, including Aarushi Khanna and Anand Sinha of Packard Foundation; Amit Arun Shah and Subrato Kumar Mondal of USAID/India; Bubul Sood of Jhpiego; Manoj Pal of Engender Health; Priya Nanda of the Bill and Melinda Gates Foundation; and Rashmi Kukreja of Abt Associates.

We lastly acknowledge and thank all of the women who participated in the study for sharing their time and experiences. Without them this study would not have been possible. 


\title{
List of Acronyms
}

\author{
ANM Auxiliary nurse midwife \\ ASHA Accredited social health activist \\ AWW Anganwadi worker \\ CAPI Computer-assisted personal interviewing \\ DHS Demographic and Health Surveys \\ FP Family planning \\ IUD Intrauterine contraceptive device \\ LAM Lactational Amenorrhea Method \\ MII Method Information Index \\ NGO Nongovernmental organization \\ OCP Oral contraceptive pills \\ PPIUD Postpartum intrauterine contraceptive device \\ USAID United States Agency for International Development
}





\section{Executive Summary}

The Government of India has committed to increasing modern contraceptive use from 47.7 percent (IIPS and ICF 2017) to 54.3 percent among married women aged 15-49 by 2020 (FP2020 and Government of India 2017). To achieve this goal, India has committed to increase access, choice, and quality of family planning (FP) services by focusing on modern reversible methods. Among married women using a modern contraceptive method, 75 percent use female sterilization, 12 percent use condoms, 9 percent use oral contraceptive pills, 3 percent use IUDs, one percent use male sterilization, and 0.4 percent use injectables (IIPS and ICF 2017). Discontinuation rates for modern reversible methods are high, with 44 percent of episodes of modern reversible method use discontinued within the first year (IIPS and ICF 2017).

To better understand the dynamics of reversible modern contraceptive use in India, The Evidence Project, led by the Population Council with support from the United States Agency for International Development (USAID)/India, conducted a prospective cohort study of married women in India who initiated a reversible modern contraceptive method. The objectives of the study were to:

- Explore one-year contraceptive use dynamics among a cohort of modern reversible contraceptive users by modern method (oral contraceptive pill, IUD, injectable).

- Understand the reasons for discontinuation of modern reversible contraceptive methods.

- Examine the experience of side effects of modern reversible contraceptive users.

- Assess the quality of care received by clients at time of method adoption.

- Understand experiences using and obtaining contraceptive methods over the course of 12 months.

The study enrolled a cohort of 2,699 married women aged 15-49 who initiated a new episode of using a reversible contraceptive method: postpartum intrauterine device (PPIUD), interval IUD, injectable contraceptive, or oral contraceptive pill (OCP). New episodes of use included women who had never used a method before and those that had previously used a method but were not using at the time of study enrollment. Women were interviewed in-person at four time points: within one month of initiating the method (enrollment), and 3, 6, and 12 months later. The study was conducted in Haryana and Odisha states, and women were enrolled primarily at government and non-governmental organization (NGO) facilities and through accredited social health activists (ASHAs) at the community level. Respondents were purposively sampled; therefore, proportions are not representative at the state level or representative of method-specific family planning users. The study was reviewed and approved by the ethics committee of the Government of Odisha and by the Institutional Review Board of the Population Council. All women enrolled into the study gave written consent for voluntary participation in the study before enrollment and before all follow-up interviews.

Of the 2,699 women enrolled into the study, 412 began using the PPIUD at enrollment, 640 began using the interval IUD, 581 began using the injectable, and 1,066 began using OCPs. At enrollment, 71 percent of the women were between 20 and 29 years old, 84 percent were Hindu, 51 percent had secondary or higher levels of education, and 99 percent had at least one child. Fifty-nine percent did not want to have any more children in the future at the time of the enrollment interview. Fifty-two percent had used a modern method of contraception in the past. Key findings of the study included:

Across four domains of quality of care (respectful care, information exchange to enable appropriate method selection, effective use of method selected, and continuity of contraceptive use and care), PPIUD users consistently reported receiving lower levels of quality of care than users of other methods. At enrollment, 38 percent of OCP users, 38 percent of interval IUD users, 35 percent of injectable users, and 17 percent of 
PPIUD users reported receiving the Method Information Index Plus (MIIplus), meaning they answered "yes" to four questions: 1) Were you told about other methods, 2) Were you told about potential side effects of the method you selected, 3) Were you told what to do if you experience side effects/problems with the method you selected, and 4) Were you told about the possibility of switching methods if the method you selected was not suitable? Among users of the PPIUD, interval IUD, and OCP, receipt of the MIIplus increased with wealth tertile.

Implications: Quality of care should be improved for users of all modern methods of family planning, and especially for PPIUD users and women of lower wealth status. Quality of care improvement efforts should also be routinely monitored and tracked to ensure that women are receiving high quality services. Providers of all cadres should be trained on respectful care, and information exchange on appropriate method selection, effective use of methods, and continuity of contraceptive use and care.

Over the course of 12 months, 23 percent of women $(n=2,559)$ reported experiencing side effects of their enrollment method, including 50 percent of injectable users, 22 percent of PPIUD users, 22 percent of interval IUD users, and 11 percent of OCP users. Eighteen percent of women reported talking to someone about side effects, and 12 percent talked to their provider/ASHA about the side effects they experienced. Common side effects experienced were abdominal cramping/pain among PPIUD users (10\%) and interval IUD users (13\%); heavy menstruation among PPIUD users $(9 \%)$ and injectable users $(12 \%)$; and absence of menstruation among injectable users $(25 \%)$.

Among women who discontinued the enrollment method $(\mathrm{n}=921)$ at some point during the study, 24 percent did so because of side effects experienced or health concerns. An additional 20 percent reported not menstruating since starting the method as the reason why they discontinued the method. Not menstruating was the most common reason why women who initiated the injectable stopped using the method. Twelve percent discontinued because they wanted to become pregnant, and 10 percent discontinued because their husband was not living at home, suggesting these women no longer had a need for family planning.

Implications: Most women (77\%) did not report experiencing side effects of their enrollment method, though many who discontinued the enrollment method did so due to side effects or other health concerns. Contraceptive initiators should receive follow-up visits from frontline health workers to provide support and answer questions related to the method selected. These visits could assist women with information on managing side effects or switching to a different method.

While most women — 61 percent—continued to use the method they adopted at enrollment throughout the year, considerable movement among contraceptive use states was observed, including switching to different FP methods, continuing use of the switched methods, or discontinuing contraceptive use altogether. Interval IUD $(74 \%)$ and OCP (75\%) users were most likely to continue to use these methods they began at enrollment, followed by PPIUD users (66\%). Less than half (44\%) of injectable users continued to use injectables. Overall, discontinuation of all contraception was low, at 13 percent. However, half of those not using any method did not want to have any more children in the future, 7 percent wanted to wait more than two years, and 12 percent didn't know. These women, a total of 69 percent of non-users, therefore had an unmet need for contraception at the end of one year. These findings highlight the importance of providers and ASHAs offering continuous support to women who want to delay or prevent pregnancy that includes opportunities to switch methods as their fertility desires change over time. Information and FP methods offered to women at the initial FP visit alone is not enough to ensure that women continuously meet their needs for voluntary contraceptive use; continuous follow-up is needed. 
Implications: Discontinuation of contraceptive use altogether after one year was relatively low. There was considerable movement between various states of contraceptive use. Women did switch to other methods, both modern as well as traditional methods. Among those who were not using at 12 months, however, the majority had an unmet need for family planning. At the time of method adoption and after the initial visit, it is important to continue to offer women information about the possibility of switching to other methods, including modern fertility awareness-based methods.

At enrollment, most women wanted to use their family planning method for limiting (59\%) or delaying childbearing for at least two years $(28 \%)$. While these preferences appeared to be relatively stable over time, there were substantial variations in fertility preferences over the course of the study at the individual level. For example, when examining the data longitudinally, over one-third (35\%) of women who did not want to have any children at enrollment changed their mind and reported wanting to have more children in at least one follow-up interview. Additionally, a significant proportion didn't know whether or when they wanted to have another child in at least one interview, as 6 percent of respondents at enrollment and 15 percent after one year were unsure. Being unsure of fertility preferences is a legitimate response that may change over time, and providers and ASHAs should be sure to ask women about their fertility preferences at each interaction. When asking women about their fertility desires, a better understanding of their motivations to prevent pregnancy and under what circumstances they may change their mind may help providers support women in selecting appropriate methods.

Implications: These data show that while fertility intentions appear to remain relatively consistent over a year, women's desires can and do change. Asking women about their fertility intentions and motivation to prevent pregnancy routinely in FP counseling can help ensure that women are selecting methods that best meet their changing reproductive needs.

After one year, 62 percent of respondents did not want to have any more children. While those using modern methods after one year were most likely to report not wanting to have any more children $(64 \%)$, over half of those using traditional methods (56\%) and half of those not using any method (50\%) did not want any more children either. These women would be potential candidates for modern methods of contraception and should be supported in switching to a different modern method according to their reproductive needs. Since such a large proportion of modern, traditional, and non-users of family planning desired no more children, and since this was the strongest fertility preference among this sample of women, there is a rationale to continue supporting the female sterilization program in India. Coupled with counseling about fertility preferences and motivation to prevent pregnancy, this could help enable women in India with an unmet need for FP for limiting births to meet their reproductive intentions.

Implications: India should continue to expand the basket of methods available to women while supporting sterilization as part of the national family planning program.

Seven percent of women experienced a pregnancy at some point during the study (including women who were using and not using a contraceptive method at the time they became pregnant). Of the 183 women who experienced a pregnancy during the study period, half (51\%) did not want to become pregnant at all, did not want to become pregnant at that time, or didn't know. Less than 10 percent of women who experienced a pregnancy terminated the pregnancy.

Implications: As half of pregnancies experienced in this study were not wanted at all or at that time, there is a need to ensure that women are offered an array of methods to switch to in order to prevent unwanted pregnancies. 


\section{Introduction}

Use of modern contraceptive methods in India has steadily increased from 37 percent among married women aged 15-49 in 1992-93 (IIPS 1995) to 48 percent in 2015-16 (IIPS and ICF 2017). At the London Summit on Family Planning in 2017, the Government of India articulated a commitment to increase modern contraceptive use to 54.3 percent among married women of reproductive age by increasing access, choice, and quality of family planning (FP) services (FP2020 and Government of India 2017). As part of its FP2020 commitment, India aims to expand method choice available to women by focusing on modern reversible methods, including the intrauterine contraceptive device (IUD) and postpartum IUD (PPIUD).

Currently, the method mix in India is heavily skewed toward female sterilization. It is used by 75 percent of married women who are using a modern contraceptive method (IIPS and ICF 2017). Other methods used include condoms (12\%), oral contraceptive pills (OCPs) (9\%), IUD (3\%), male sterilization (1\%), and injectables $(0.4 \%)$. Discontinuation rates for these reversible methods, however, remain high, as 44 percent of episodes of use of all modern reversible methods are discontinued within one year (IIPS and ICF 2017). Oneyear discontinuation rates are highest for injectables (51\%), followed by condoms (47\%), OCPs (42\%), and the IUD $(26 \%)$. While 12 percent discontinued because they wanted to have a child, only in 6 percent of discontinued episodes did the woman switch to a different FP method (IIPS and ICF 2017), suggesting that most women who discontinue may continue to have a need for family planning.

To enable India to meet its FP2020 goals and design programs that meet the needs of women and their families, a better understanding of contraceptive use dynamics, including contraceptive choice, discontinuation, and switching behaviors, is paramount. To fill this gap in the literature, The Evidence Project, led by the Population Council and funded by the United States Agency for International Development (USAID)/India, conducted a prospective cohort study of married women in India who initiated a reversible contraceptive method. Most research to date on contraceptive use dynamics has been on contraceptive use retrospectively. For example, the Demographic and Health Surveys (DHS) ask women to recall all episodes of contraceptive use and reasons for discontinuing those episodes in the 3-59 months prior to the interview (IIPS and ICF 2017). Asking women their reasons for discontinuing a method that may have occurred five years ago introduces the possibility of recall bias. The present study, on the other hand, was conducted prospectively over the course of one year, reducing the potential for recall bias. Additionally, this study has focused on less understood aspects of contraceptive use dynamics, including the experience of side effects and their effect on daily life, quality of care received by clients at the time of method adoption, and factors that enable method switching among modern contraceptive methods if the current method is not suitable.

This report summarizes the results of the prospective cohort study on the dynamics of reversible method use. The findings can be used to inform India's national family planning program as the government focuses on increasing access, choice, and quality of FP services with an emphasis on reversible methods. 


\section{Objectives}

The objectives of this report are to:

- Explore one-year contraceptive use dynamics among a cohort of modern reversible contraceptive users by modern method (oral contraceptive pill, IUD, injectable).

- Understand the reasons for discontinuation of modern reversible contraceptive methods.

- Examine the experience of side effects of modern reversible contraceptive users.

- Assess the quality of care received by clients at time of method adoption.

- Understand experiences using and obtaining contraceptive methods over the course of 12 months. 


\section{Methods}

\section{Study design, enrollment, and sampling}

A cohort of 2,699 married women aged 15-49 who initiated a new episode of using a reversible contraceptive method: postpartum intrauterine device (PPIUD), interval IUD, injectable contraceptive, or oral contraceptive pill (OCP), was followed for one year. A new episode of use included women who had never used a modern method of family planning previously as well as those who had used a modern method at some point in the past but had not been using a modern method just prior to study enrollment.

Women enrolled in the study were interviewed at four time points: within one month of initiating the method (enrollment), and 3, 6, and 12 months later. The study was conducted in nine districts of two Indian states (Figure 1) Nuh, Panipat, Rewari, and Sonipat districts of Haryana and Baleswar, Bhadrak, Kendujhar, Khorda, and Mayurbhanj districts of Odisha. Women were enrolled from December 2016 to October 2017.

In Haryana, women were enrolled through accredited social health activists (ASHAs) at the community level. Districts in which a private organization was implementing an injectable program and where health management information systems reported a high number of IUDs inserted in the last year were selected for inclusion in the study, as there was a higher likelihood of identifying modern reversible method users. ASHAs in these districts identified women who adopted a modern reversible method within the preceding month and asked their permission to bring a member of the research team to their home. In Odisha, PPIUD users were primarily enrolled at select government health facilities from delivery wards, though some were enrolled via ASHAs identified by the facilities. Interval IUD and OCP users were enrolled primarily through ASHAs identified by facility managers, and injectable users were enrolled primarily at non-governmental organization (NGO) facilities. Women in this study were sampled purposively. Proportions presented in this report are limited to the sampled population only and are not to be interpreted as representative of method-specific family planning users. In addition, while combined results are presented for all women surveyed in this study, estimates are not representative at the state or district levels.

All interviews were conducted in-person. In both states, women enrolled at facilities were interviewed at the facility upon being approached by the research team and providing informed consent. Women who were enrolled through ASHAs gave their consent to the ASHA to be contacted by the research team. The research team then contacted the women to determine a location for the interview, either at home or at the facility, per the respondent's preference. Follow-up interviews were also conducted in-person, either at home or at the facility. Women who were not reachable at the 3-month or 6-month interview could reenter the study at a later interview time. Of 2,699 women interviewed at enrollment, 2,306 were re-interviewed 3 months later, 2,396 6 months later, and 2,441 12 months later, resulting in a follow-up rate of $85.4-90.4$ percent for the year (Table 1). 
TABLE 1. PROPORTION OF ENROLLED RESPONDENTS INTERVIEWED AT EACH TIME-POINT, BY ENROLLMENT METHOD

\begin{tabular}{lccccccc}
\hline & Enrollment & \multicolumn{2}{c}{ Month 3 } & \multicolumn{2}{c}{ Month 6 } & \multicolumn{2}{c}{ Month 12 } \\
\cline { 2 - 8 } & $\mathrm{n}$ & $\mathrm{n}$ & $\%$ & $\mathrm{n}$ & $\%$ & $\mathrm{n}$ & $\%$ \\
\hline PPIUD & 412 & 327 & 79.4 & 344 & 83.5 & 358 & 86.9 \\
Interval IUD & 640 & 545 & 85.2 & 556 & 86.9 & 564 & 88.1 \\
Injectable & 581 & 455 & 78.3 & 495 & 85.2 & 510 & 87.8 \\
OCP & 1,066 & 979 & 91.8 & 1,001 & 93.9 & 1,009 & 94.7 \\
\hline Combined & 2,699 & 2,306 & 85.4 & 2,396 & 88.8 & 2,441 & 90.4 \\
\hline
\end{tabular}

\section{Data collection}

\section{Data collector training}

One study coordinator and five female data collectors were hired in each state. Study coordinators managed all data collection activities, and female data collectors enrolled all participants and conducted all interviews. Study coordinators were trained in New Delhi on the study objectives, study instruments, and data collection using a computer-assisted personal interviewing (CAPI) package. Intensive, one-week trainings of data collectors were conducted in each state by the research team and respective study coordinator. Trainings covered the study objectives and purpose, a review of each question and its purpose, a review of informed consent forms, use of data collection software and CAPI package, and data management including data flow and file backup. The training also specifically focused on the ethical aspects of the study, including the meaning and process of informed consent, the importance of protecting the privacy of respondents, and confidentiality of the information obtained from respondents. Three-day trainings were conducted prior to each follow-up interview to refresh data collectors' knowledge and orient them to the new questionnaires.

\section{Data collection}

Female data collectors interviewed respondents face-to-face at four time points using mini-laptops. The CAPI package was developed in Hindi and Odia, the local languages of Haryana and Odisha. Informed consent was obtained prior to the enrollment interview and each of the three follow-up interviews.

At enrollment, data collectors asked respondents about a range of information including demographic data, fertility intentions, previous contraceptive use, birth history, counseling received at the time of method initiation, satisfaction with this visit, contact with frontline health workers, knowledge of contraceptive methods, reproductive autonomy, household decision making, empowerment, attitudes toward domestic violence, and couple's communication about sex. At follow-up interviews, respondents provided information on changes in family structure and employment, fertility intentions, current contraceptive use, experiences and management of side effects (if experienced), experiences obtaining OCP and injectable doses, and followup services for IUD. For those who discontinued, additional questions were asked about reasons for discontinuation, whom the respondents spoke to about the desire to discontinue, counseling received for respondents who switched to a new method, and, for those who did not switch to a new method, their intention to use a contraceptive in the future.

\section{Data management and analysis}

Data collection supervisors collated the data and sent it to the research team in New Delhi, India, where the data were carefully reviewed for errors. The research team routinely checked for inconsistencies and cleaned the data when possible throughout the study period. Respondents were given unique identifiers to enable them to be linked for follow-up interviews, and these unique identifiers were known only to the research 
team and stored in a password-protected computer. The text responses for "others (specify)" were examined and recoded.

Descriptive statistics and bivariate analyses by enrollment method were conducted. Data analysis was conducted by enrollment method because strategies for enrollment were different for each method. Chisquare tests were used to determine significant differences in experiencing pregnancy by enrollment method and in receiving the MIIplus (Method Information Index Plus) by respondent characteristics.

\section{Ethical review}

The study was reviewed and approved by the ethics committee of the Government of Odisha and by the Institutional Review Board of Population Council. All respondents gave written consent for voluntary participation in the study before the enrollment interview and before each of the three follow-up interviews. 


\section{Results}

The results section of this report presents an overview of the characteristics of the women enrolled in the study, their experiences with the enrollment method, including quality of care at the time of method adoption, experiences of side effects, and reasons for discontinuation of the enrollment method. The report then presents women's contraceptive use dynamics after one year, including changes in contraceptive use, fertility preferences, experiences using and obtaining contraceptive methods, and experiences of pregnancy during the 12-month period.

\section{Respondent characteristics}

Table 2 shows the demographic characteristics of respondents at enrollment by method initiated. Most women enrolled into the study were between 20 and 29 years old (71\%) and Hindu (84\%). Overall, 38 percent of the women belonged to marginalized communities, i.e., scheduled castes and scheduled tribes. Twenty-three percent of women had never attended school, while just over half (51\%) had secondary levels of education or higher. Most were housewives (94\%), though a small proportion were manual laborers (2\%), worked in white collar jobs $(1.9 \%)$, or were farmers $(1.5 \%)$.

Forty-one percent of women had one child at the time of enrollment while one-third (33\%) had two children and one-quarter $(25 \%)$ had three or more. Less than one percent did not have any living children $(0.7 \%)$. At enrollment, three in five women (59\%) did not want to have any more children in the future, 6 percent wanted to have a child within two years, and just over one-quarter $(28 \%)$ wanted to have a child in more than two years. Seven percent didn't know or were undecided about when they wanted to have a child. Over half of the women had used a modern method of contraception in the past (52\%). Twelve percent had used only traditional methods ${ }^{1}$ previously, while over one-third $(36 \%)$ had previously never used a contraceptive method.

Nearly half of respondents $(49 \%)$ had obtained their current method from public health facilities, while 33 percent obtained it from a frontline health worker, 13 percent from an NGO, 3 percent from a medical store, and 3 percent from a private facility. Public health facilities include district hospitals, community health centers, primary health centers, and sub-centers. Frontline health workers include accredited social health activists (ASHAs), Anganwadi workers (AWW), and auxiliary nurse midwives (ANM). ANMs are permitted to insert IUDs in India and are based at primary health centers and sub-centers (Scott et al. 2014). Thus, while some PPIUD and IUD users received their IUD from an ANM, they are counted as receiving their IUD from a public health facility, as the IUD is not provided via community-based distribution. Additionally, while 11 percent of injectable users and 2 percent of OCP users obtained their injection from a medical store, they received counseling and a referral for their method from a provider or frontline health worker. NGO facilities are distinguished from commercial private facilities as they are within the non-profit sector.

\footnotetext{
${ }^{1}$ Traditional methods include withdrawal, abstinence, and rhythm method.
} 
TABLE 2. RESPONDENT CHARACTERISTICS BY ENROLLMENT METHOD $(\mathrm{N}=2,699)$

\begin{tabular}{|c|c|c|c|c|c|}
\hline \multirow[b]{2}{*}{ Background characteristics } & \multicolumn{4}{|c|}{ Enrollment Method } & \multirow[b]{2}{*}{$\begin{array}{l}\text { Combinec } \\
(n=2,699\end{array}$} \\
\hline & $\begin{array}{c}\text { PPIUD } \\
(n=412)\end{array}$ & $\begin{array}{c}\text { Interval IUD } \\
(n=640)\end{array}$ & $\begin{array}{c}\text { Injectable } \\
(n=581)\end{array}$ & $\begin{array}{c}\text { OCP } \\
(n=1,066)\end{array}$ & \\
\hline \multicolumn{6}{|l|}{ Age group in years } \\
\hline Below 20 years & 5.6 & 8.4 & 0.7 & 1.3 & 3.5 \\
\hline 20-24 years & 58.5 & 41.1 & 20.3 & 32.7 & 36.0 \\
\hline $25-29$ years & 27.7 & 30.8 & 36.7 & 38.6 & 34.6 \\
\hline $30-34$ years & 7.3 & 13.3 & 22.0 & 18.0 & 16.1 \\
\hline 35 years and above & 1.0 & 6.4 & 20.3 & 9.4 & 9.7 \\
\hline \multicolumn{6}{|l|}{ Religion } \\
\hline Hindu & 97.3 & 92.5 & 67.5 & 83.2 & 84.2 \\
\hline Muslim & 1.9 & 7.2 & 32.2 & 16.6 & 15.5 \\
\hline Other & 0.7 & 0.3 & 0.3 & 0.2 & 0.3 \\
\hline \multicolumn{6}{|l|}{ Caste/tribe } \\
\hline Scheduled caste & 15.5 & 13.8 & 13.4 & 23.4 & 17.7 \\
\hline Scheduled tribe & 33.7 & 31.7 & 5.7 & 16.0 & 20.2 \\
\hline Other backward class & 19.4 & 28.4 & 30.1 & 29.1 & 27.7 \\
\hline General & 30.3 & 23.0 & 41.1 & 29.0 & 30.4 \\
\hline Other & 1.0 & 3.1 & 9.6 & 2.6 & 4.0 \\
\hline \multicolumn{6}{|l|}{ Education } \\
\hline No education & 16.8 & 23.6 & 30.3 & 20.9 & 22.9 \\
\hline Primary & 16.0 & 9.2 & 10.5 & 12.7 & 11.9 \\
\hline Middle & 16.3 & 13.3 & 13.1 & 14.8 & 14.3 \\
\hline Secondary & 35.9 & 25.2 & 24.6 & 32.8 & 29.7 \\
\hline Higher secondary & 9.5 & 17.3 & 9.6 & 11.3 & 12.1 \\
\hline Above higher secondary & 5.6 & 11.4 & 11.9 & 7.5 & 9.1 \\
\hline \multicolumn{6}{|l|}{ Employment } \\
\hline Housewife & 92.2 & 91.9 & 93.6 & 95.4 & 93.7 \\
\hline Business & 0.5 & 0.6 & 0.7 & 0.8 & 0.7 \\
\hline Farmer & 1.5 & 4.8 & 0.2 & 0.3 & 1.5 \\
\hline Manual labor & 4.9 & 1.1 & 2.4 & 1.6 & 2.1 \\
\hline White collar jobs & 1.0 & 1.6 & 3.1 & 1.9 & 1.9 \\
\hline \multicolumn{6}{|l|}{ Parity^^} \\
\hline No children & 0.7 & 0.3 & 0.3 & 1.1 & 0.7 \\
\hline 1 child & 59.7 & 38.9 & 25.5 & 44.6 & 41.4 \\
\hline 2 children & 31.1 & 36.9 & 38.4 & 28.6 & 33.0 \\
\hline $3+$ children & 8.3 & 23.7 & 35.8 & 25.7 & 24.7 \\
\hline \multicolumn{6}{|l|}{ Fertility preferences } \\
\hline Did not want any more children & 43.7 & 61.6 & 78.0 & 53.0 & 59.0 \\
\hline Desired within the next year & 0.0 & 1.3 & 0.5 & 1.8 & 1.1 \\
\hline Desired within 1 to 2 years & 2.7 & 3.3 & 5.9 & 7.5 & 5.4 \\
\hline Desired after more than 2 years & 49.3 & 26.9 & 12.1 & 28.7 & 27.8 \\
\hline Did not know when & 4.4 & 7.0 & 3.6 & 9.0 & 6.7 \\
\hline \multicolumn{6}{|l|}{ Previous contraceptive use } \\
\hline Modern method & 31.1 & 49.5 & 64.0 & 55.6 & 52.2 \\
\hline Traditional methods only & 11.4 & 13.9 & 9.0 & 11.3 & 11.5 \\
\hline No previous contraceptive use & 57.5 & 36.6 & 27.0 & 33.1 & 36.3 \\
\hline \multicolumn{6}{|l|}{ Current method source } \\
\hline Public health facility & 100 & 90.5 & 37.4 & 10.5 & 48.9 \\
\hline Frontline health worker & 0.0 & 0.0 & 1.7 & 82.0 & 32.8 \\
\hline Medical store & 0.0 & 0.0 & 11.4 & 1.3 & 3.0 \\
\hline Private facility & 0.0 & 6.3 & 3.8 & 0.8 & 2.6 \\
\hline NGO & 0.0 & 3.3 & 45.8 & 5.4 & 12.8 \\
\hline
\end{tabular}

^Percentages may not add to $100 \%$ due to missing values 


\section{Quality of care received at enrollment}

At enrollment into the study, all women were asked about the quality of care they received during their visit with a provider or a frontline health worker to obtain their family planning method. Though 3 percent obtained their method (injectable or OCP) from a medical store, the counseling for the method was done by a provider at a public facility or by a frontline health worker. This study did not observe providers during the family planning counseling interactions, but rather captured the care and information received as reported by clients after the interaction. Clients were interviewed within one month of receiving their enrollment method, in efforts to minimize recall bias.

Measures of quality were broken down into four domains of process quality (Jain, Townsend \& Ramarao 2018; Jain et al. 2019a):

1) Respectful care relates to interpersonal interactions between provider and client and assesses aspects of privacy and confidentiality.

2) Method selection focuses on exchange of information between a provider and client to enable selection of an appropriate method.

3) Effective use of the selected method includes information given to the client about the selected method.

4) Continuity of contraceptive use and care covers information on follow-up appointments and the ability to switch methods or sources of family planning.

Figure 2 presents aspects of respectful care received by women when they initiated the enrollment method. Nearly all women reported they were treated well by the provider (99-100\%), regardless of method received. For other indicators, a greater proportion of injectable and OCP users reported receiving respectful care compared to interval IUD and PPIUD users. For example, 97 and 99 percent of OCP and injectable users, respectively, reported that their questions were answered to their satisfaction, while this was reported by 86 percent of interval IUD and 70 percent of PPIUD users. Eighty-two percent of injectable and OCP users felt they had visual privacy during their counseling session, compared to 68 percent of IUD and 53 percent of PPIUD users.

FIGURE 2. RESPECTFUL CARE AT INITIAL VISIT BY ENROLLMENT METHOD

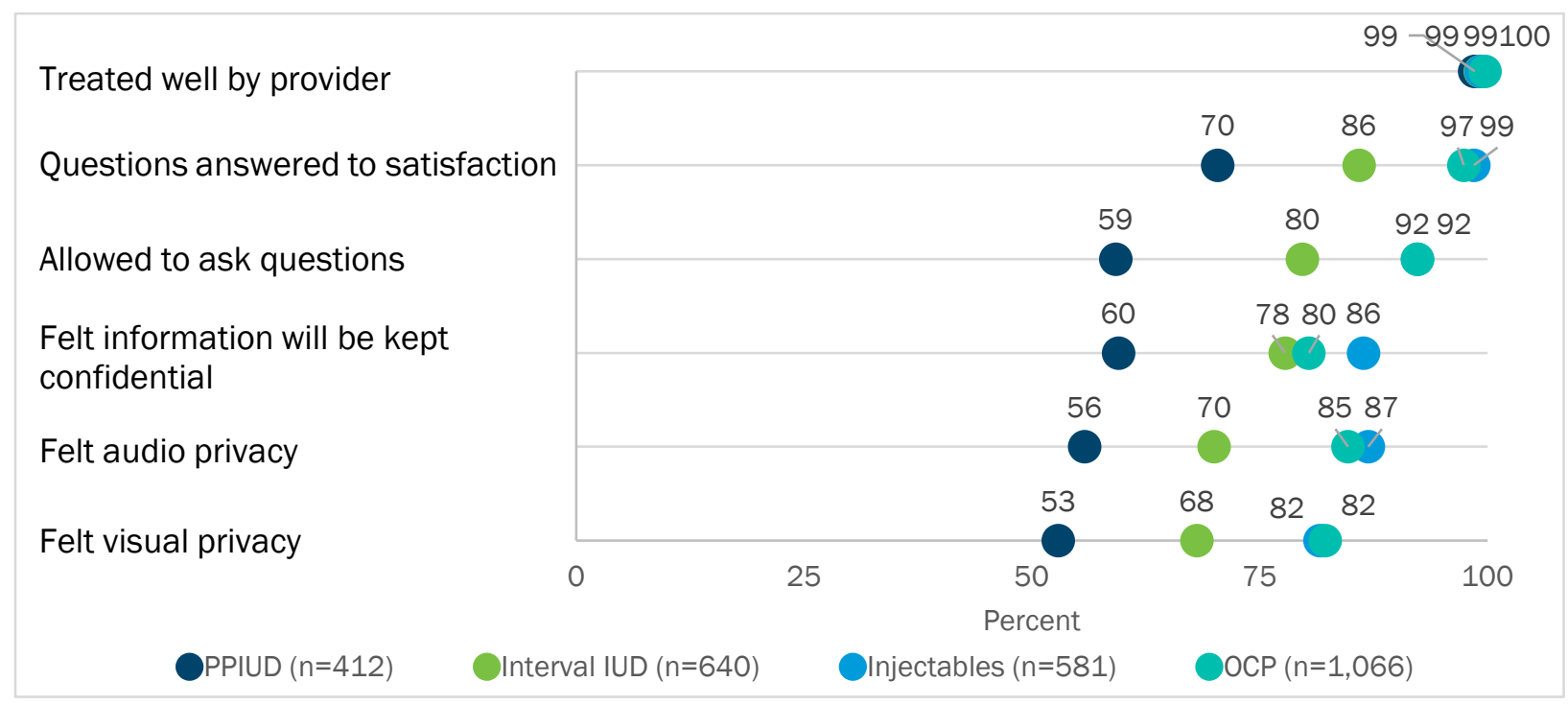


Figure 3 presents women's reporting of information received and questions asked by the provider that would enable appropriate method selection. Fewer PPIUD users reported being asked about or receiving information for method selection compared to interval IUD, injectable, or OCP users. Eighty-six percent of OCP and injectable users and 73 percent of interval IUD users reported being asked about their preferred FP method compared to only 31 percent of PPIUD users. Less than half of all users received information about methods that protect against STIs or HIV (10\% of PPIUD users, $40 \%$ of injectable and OCP users, and 47\% of interval IUD users) or received information without any one method being promoted (29\% of PPIUD and OCP users, $32 \%$ of interval IUD users, and $38 \%$ of injectable users).

FIGURE 3. METHOD SELECTION AT INITIAL VISIT BY ENROLLMENT METHOD

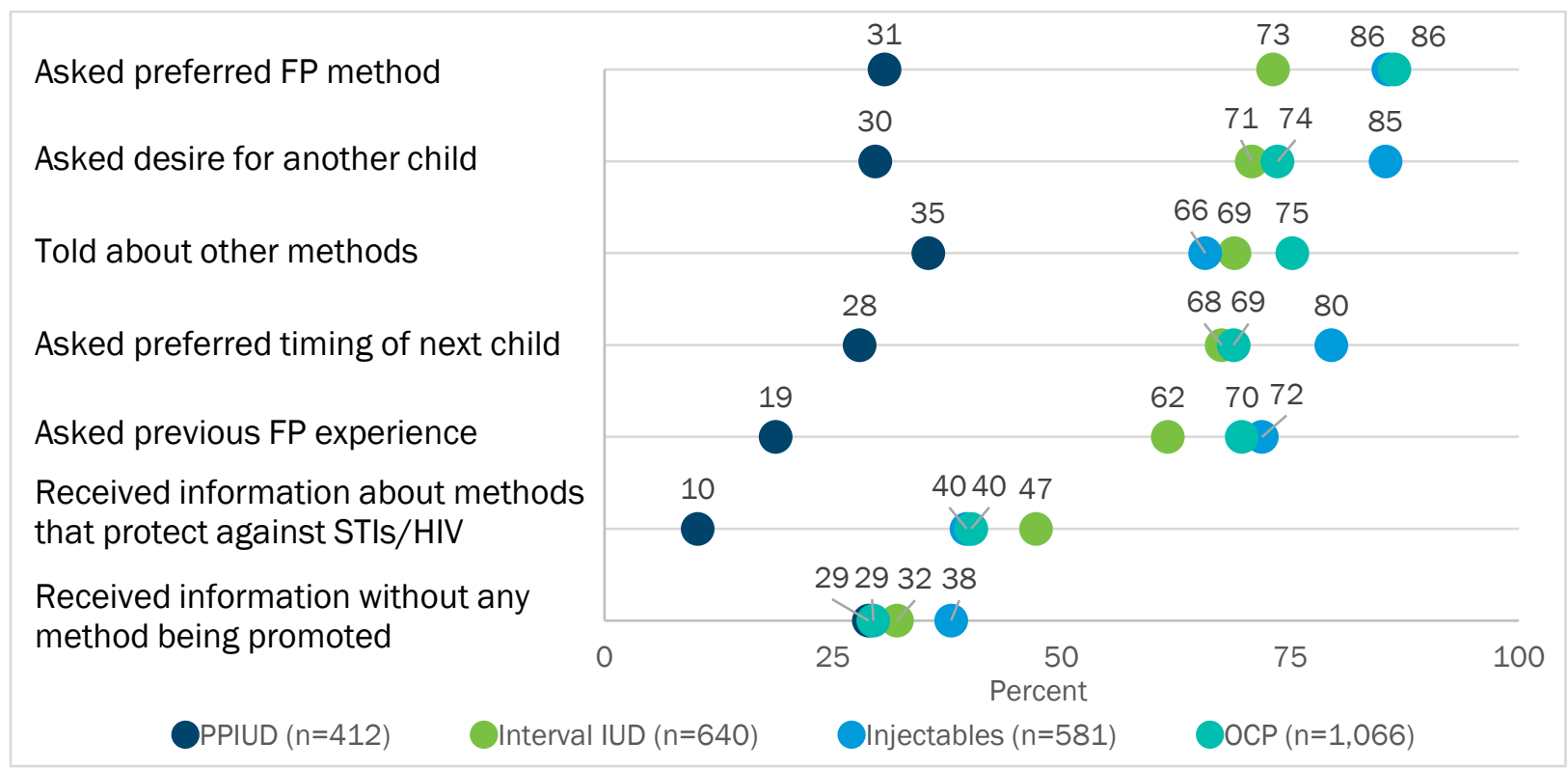


Women were asked about the information that they were given about effective use of the method that they selected at enrollment (Figure 4). While only 53 percent of PPIUD users were told how to use the selected method, 85 percent of IUD, 92 percent of injectable, and 97 percent of OCP users reported receiving this information. Most women reported that they were told how their chosen method works: 66 percent of PPIUD users, 67 percent of injectable users, 79 percent of IUD users, and 91 percent of OCP users. Fewer women, however, reported that they were told about method-related side effects ( $27 \%$ of PPIUD, $47 \%$ of interval IUD, $48 \%$ of OCP, and $58 \%$ of injectable users), how to manage side effects/problems ( $25 \%$ of PPIUD, $44 \%$ of OCP, $45 \%$ of interval IUD, and $45 \%$ of injectable users), and the warning signs (severe adverse effects) associated with the method selected (27\% of PPIUD, $33 \%$ of OCP, $43 \%$ of injectable, and $45 \%$ of interval IUD users).

\section{FIGURE 4. EFFECTIVE USE OF SELECTED METHOD AT INITIAL VISIT BY ENROLLMENT METHOD}

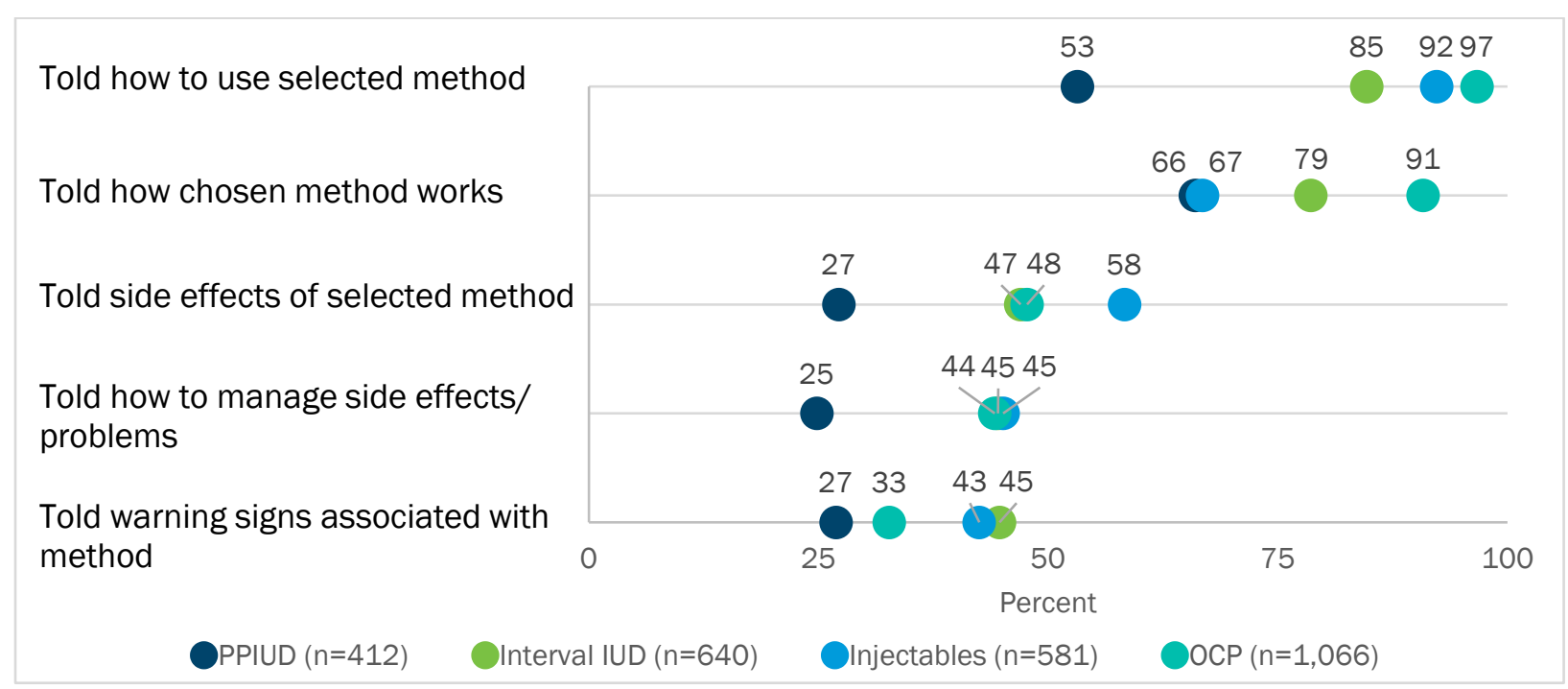


Figure 5 presents the final domain of quality of care: clients' reports of information given to enable continuity of contraceptive use and care. More PPIUD (74\%), interval IUD (81\%), and injectable users (81\%) were told about the timing of their next visit compared to OCP users (47\%). Being told about the possibility of switching methods if current method was not suitable ranged from a low of 41 percent among PPIUD users to 71 percent of interval IUD users. The percentage of women who were told about other sources of contraceptive supply ranged from 41 percent of PPIUD users to 70 percent of OCP users. Seventy-five percent of injectable users, 50 percent of interval IUD users, and 36 percent of PPIUD users were given an appointment card for their next visit. Few OCP users (9\%) were given an appointment card.

\section{FIGURE 5. CONTINUITY OF CONTRACEPTIVE USE AND CARE AT INITIAL VISIT BY ENROLLMENT METHOD}

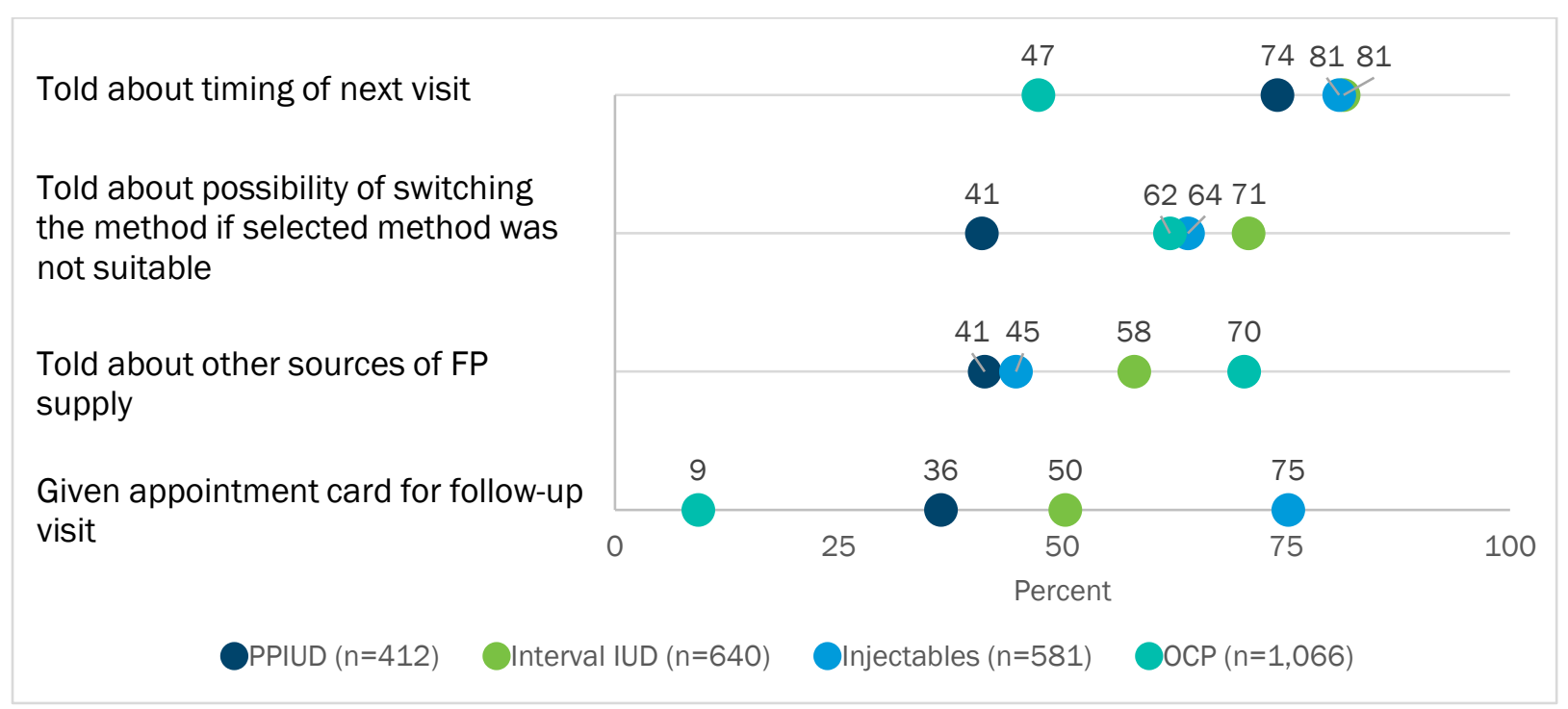




\section{Method Information Index Plus (MIIplus)}

The Method Information Index (MII) is a core indicator that FP2020 uses to track progress towards achieving 120 million additional users of contraceptives by 2020. It is an indicator of informed choice and consists of three questions: 1) Were you told about other methods, 2) Were you told about potential side effects of the method you selected, and 3) Were you told what to do if you experience side effects? Women who answered "yes" to all three are considered to have received full information of the MII.

As shown elsewhere using data from this study (Jain et al. 2019b), adding a fourth question to the MII about the possibility of switching methods if the method selected was no longer suitable better predicts contraceptive continuation three months later. This new measure, the MIIplus, is calculated as the percentage of women who answer "yes" to all four questions. Overall, few women reported receiving all four components of the MIIplus. Among PPIUD users, 17 percent reported receiving MIIplus. More than onethird of injectable (35\%), interval IUD $(38 \%)$, and OCP $(38 \%)$ users reported receiving all four components of the MIIplus (data not shown).

Figure 6 presents women's receipt of the MIIplus by women's characteristics of age, parity, education, and previous modern method use. There were no significant differences by age of women in reported receipt of the MIIplus for users of any method. Reported receipt of the MIIplus varied by education level for PPIUD and OCP users. PPIUD users and OCP users who had secondary or higher levels of education were more likely to report receiving complete MIIplus. In addition, there was a significant difference in women who reporting receiving MIIplus by parity for interval IUD and OCP users. Among interval IUD users, receipt of MIIplus was lowest for those with none or one child, at 33 percent, compared to 43 percent among those with three or more children. OCP users with two children were least likely to report receiving MIIplus, at 32 percent, compared to 43 percent of those with at least three children. Previous modern method use influenced the MIIplus information received for interval IUD (46\%), injectable (40\%), and OCP (49\%) users. Receipt of the MIIplus was significantly different by wealth tertile for users of PPIUD ( $5 \%$ of those in the lowest tertile compared to $24 \%$ in the highest), interval IUD (24\% in the lowest tertile compared to $53 \%$ in the highest), and OCP users (20\% in the lowest and 59\% in the highest). For injectable and OCP users, receipt of the MIIplus was less likely for those in rural areas (30\% of injectable and $36 \%$ of OCP) than those in urban areas ( $42 \%$ of injectable and $49 \%$ of OCP users). 
FIGURE 6. RECEIPT OF COMPLETE INFORMATION ON THE MIIPLUS AT ENROLLMENT, BY METHOD AND RESPONDENT CHARACTERISTICS

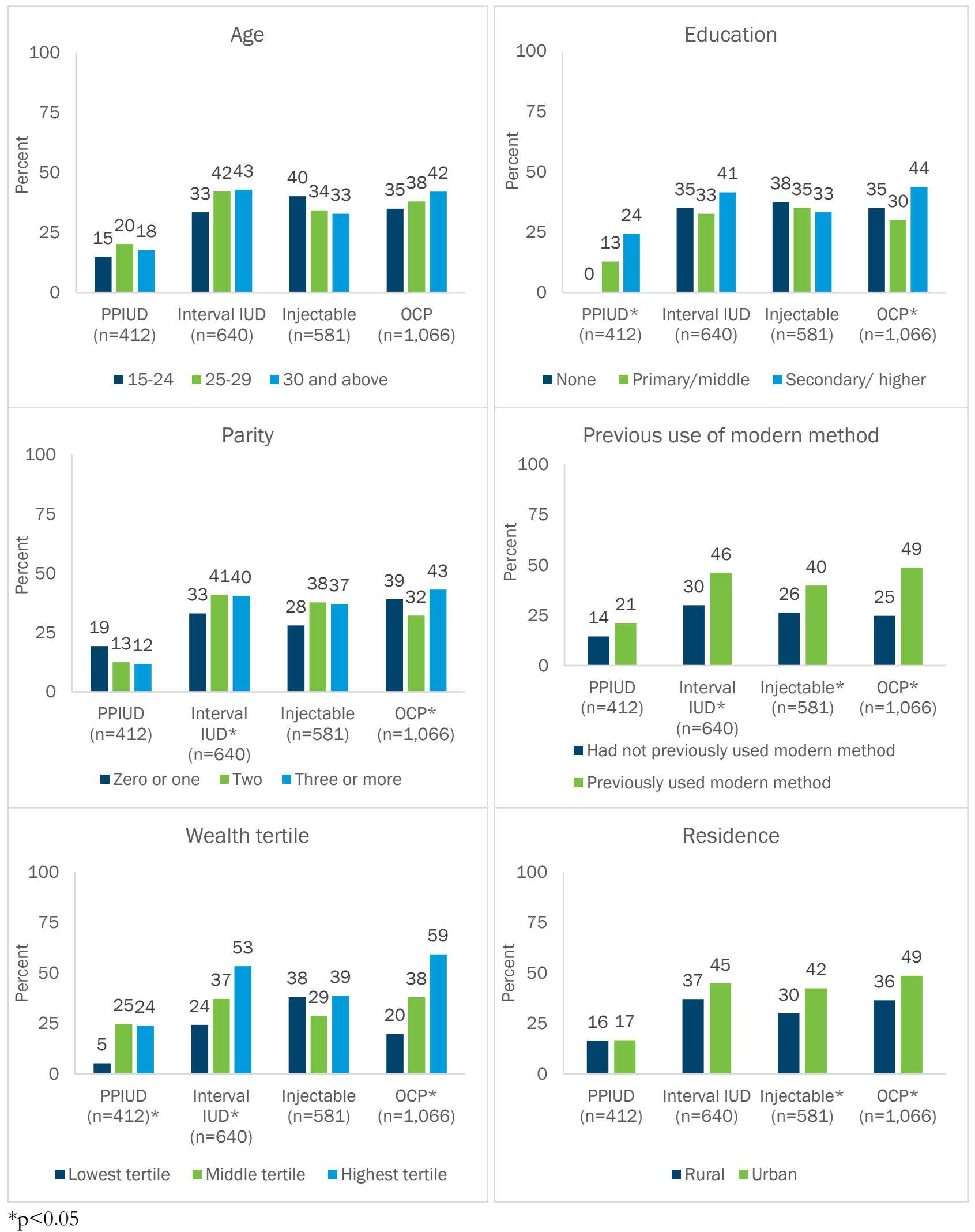




\section{Experiences of side effects on enrollment method}

Women who completed at least one follow-up interview $(n=2,559)$ were asked whether they had experienced side effects while using the enrollment method. This included women who had continued using the enrollment method, discontinued it, or switched to a different method at any follow-up interview. Those who continued using the enrollment method throughout the study were asked about side effects of that method at each follow-up interview. Women who discontinued were asked about their side effects of the discontinued enrollment method at the first follow-up interview after discontinuation.

Table 3 presents women's experiences of side effects. Throughout the 12-month study period, 23 percent of respondents experienced side effects while using their enrollment method. Half of injectable users (50\%) reported experiencing side effects of the method. Lower proportions of PPIUD $(22 \%)$ and interval IUD $(22 \%)$ users reported experiencing side effects. Eleven percent of OCP users reported experiencing side effects of the method.

Among all contraceptive users, the three most commonly reported side effects were heavy bleeding (6\%), abdominal pain/cramping (6\%), and no bleeding (6\%). For method-specific side effects, 25 percent of injectable users reported no bleeding as a side effect of the method. For PPIUD (10\%) and IUD (13\%) users, abdominal pain/cramping was the most common side effect, while weakness and dizziness (4\% each) were the most common for OCP users.

TABLE 3. EXPERIENCES OF SIDE EFFECTS ON ENROLLMENT METHOD, BY ENROLLMENT METHOD

\begin{tabular}{|c|c|c|c|c|c|}
\hline & \multicolumn{4}{|c|}{ Enrollment Method } & \multirow[b]{2}{*}{$\begin{array}{l}\text { Combined } \\
(\mathrm{n}=2,559)\end{array}$} \\
\hline & $\begin{array}{l}\text { PPIUD } \\
(n=376)\end{array}$ & $\begin{array}{l}\text { Interval IUD } \\
(\mathrm{n}=620)\end{array}$ & $\begin{array}{l}\text { Injectable } \\
(n=531)\end{array}$ & $\begin{array}{c}\text { OCP } \\
(n=1,032)\end{array}$ & \\
\hline $\begin{array}{l}\text { Experienced side effects on } \\
\text { enrollment method }\end{array}$ & 22.3 & 21.8 & 49.7 & 10.8 & 23.2 \\
\hline \multicolumn{6}{|l|}{ Side effects experienced ${ }^{\dagger}$} \\
\hline Heavy bleeding & 8.8 & 4.8 & 12.2 & 1.5 & 5.6 \\
\hline Abdominal pain/cramping & 10.4 & 12.6 & 3.0 & 1.0 & 5.6 \\
\hline No bleeding & 0.5 & 0.5 & 25.1 & 0.2 & 5.5 \\
\hline Weakness & 4.0 & 2.7 & 4.5 & 3.9 & 3.8 \\
\hline Dizziness & 2.1 & 1.9 & 3.8 & 4.2 & 3.2 \\
\hline Little bleeding & 1.3 & 1.8 & 9.2 & 0.7 & 2.8 \\
\hline Backache & 1.3 & 4.4 & 2.3 & 0.1 & 1.8 \\
\hline Irregular menstruation & 0.3 & 0.7 & 5.8 & 0.5 & 1.6 \\
\hline Nausea & 0.5 & 0.7 & 1.3 & 1.9 & 1.3 \\
\hline Headache & 0.8 & 0.7 & 1.7 & 1.0 & 1.0 \\
\hline Weight gain & 0.0 & 0.0 & 3.8 & 0.5 & 1.0 \\
\hline Swollen feet & 0.5 & 0.2 & 1.5 & 0.8 & 0.7 \\
\hline Vomiting & 0.3 & 0.5 & 0.8 & 1.0 & 0.7 \\
\hline Vaginal discharge & 2.9 & 0.8 & 0.2 & 0.1 & 0.7 \\
\hline Weight loss & 0.3 & 0.3 & 1.9 & 0.1 & 0.6 \\
\hline Spotting & 0.3 & 0.3 & 1.9 & 0.0 & 0.5 \\
\hline Vaginal itch & 0.8 & 0.7 & 0.8 & 0.0 & 0.4 \\
\hline Breast pain, tenderness, or & 0.0 & 0.3 & 0.4 & 0.2 & 0.2 \\
\hline \multicolumn{6}{|l|}{ swelling } \\
\hline Vaginal inflammation & 0.3 & 0.5 & 0.0 & 0.0 & 0.2 \\
\hline Fever & 0.0 & 0.2 & 0.6 & 0.0 & 0.2 \\
\hline High blood pressure & 0.0 & 0.2 & 0.0 & 0.0 & 0.0 \\
\hline Low blood pressure & 0.0 & 0.0 & 0.0 & 0.1 & 0.0 \\
\hline Other & 0.5 & 0.7 & 3.4 & 0.5 & 1.1 \\
\hline Don't know & 1.1 & 0.0 & 1.7 & 0.2 & 0.6 \\
\hline
\end{tabular}


† Multiple responses possible

On average, across all methods initiated at enrollment, 18 percent of women reported talking to somebody about side effects experienced (Table 4). Twelve percent reported talking to a provider or ASHA about their side effects and nearly all of those (11\% of total) reported returning to the same provider/ASHA or facility to discuss side effects. Speaking to a provider or ASHA about side effects varied by method ranging from a high of 25 percent among injectable users to a low of 6 percent among OCP users.

TABLE 4. REACTIONS TO SIDE EFFECTS OF ENROLLMENT METHOD AMONG WOMEN WHO EXPERIENCED SIDE EFFECTS, BY ENROLLMENT METHOD

\begin{tabular}{lccccc}
\hline & \multicolumn{4}{c}{ Enrollment method } \\
\cline { 2 - 5 } & $\begin{array}{c}\text { PPIUD } \\
(\mathrm{n}=\mathbf{3 7 6})\end{array}$ & $\begin{array}{c}\text { Interval IUD } \\
(\mathrm{n}=620)\end{array}$ & $\begin{array}{c}\text { Injectable } \\
(\mathrm{n}=531)\end{array}$ & $\begin{array}{c}\text { OCP } \\
(\mathrm{n}=\mathbf{1 , 0 3 2})\end{array}$ & $\begin{array}{c}\text { Combined } \\
(\mathrm{n}=\mathbf{2 , 5 5 9 )}\end{array}$ \\
\hline $\begin{array}{l}\text { Talked to somebody about } \\
\text { experiencing side effects }\end{array}$ & 16.5 & 17.1 & 39.2 & 7.7 & 17.8 \\
$\begin{array}{l}\text { Talked to a provider or ASHA } \\
\text { about side effects }\end{array}$ & 9.8 & 11.8 & 24.9 & 5.9 & 11.8 \\
$\begin{array}{l}\text { Returned to same } \\
\text { provider/ASHA or facility to } \\
\text { discuss side effects }\end{array}$ & 9.6 & 11.3 & 22.8 & 5.5 & 11.1 \\
\hline
\end{tabular}

Women who experienced side effects were likely to discontinue using their contraceptive method after one year. Among those who experienced side effects on their enrollment method, only 39 percent of those interviewed in the 12-month interview ( $\mathrm{n}=576$ ) were still using their enrollment method after one year, compared to 67 percent of the total sample (data not shown). Twenty-one percent discontinued contraception altogether, while 25 percent switched to a different modern method and 15 percent switched to traditional methods (data not shown). 


\section{Reasons for discontinuation of enrollment method}

Of the 2,699 women who were enrolled into the study, 5 percent were not interviewed in any of the followup interviews. Because their contraceptive use is not known after the enrollment period, they were excluded from analyses of enrollment method discontinuation since it is not known if they discontinued the method. Of the 2,559 who were interviewed in at least one follow-up interview, 921 women (36\%) discontinued their enrollment method at some point during the study duration. This includes women who switched to other methods at the time of discontinuation or later, and those who discontinued altogether.

Table 5 presents women's spontaneously reported reasons for discontinuation of the enrollment method (multiple responses were possible, but responses were not read out). Overall, nearly one-quarter (24\%) of those who discontinued did so due to side effects/health concerns while one-fifth (20\%) discontinued the method because they had not menstruated since starting to use the method. Twelve percent discontinued because they wanted to become pregnant and 10 percent discontinued because their husband was not living at home. Nearly one-quarter $(24 \%)$ did not list a reason for discontinuing their enrollment method.

Reasons for discontinuation varied by method initiated at enrollment. For PPIUD and interval IUD discontinuers, side effects/health concerns (34\% of PPIUD users and $28 \%$ of interval IUD users) was the most common reason for discontinuing. Over half of injectable users who discontinued the method reported they had not menstruated since beginning the method (51\%). OCP discontinuers stopped using the methods to become pregnant $(20 \%)$ or because their husband was not living at home $(18 \%)$. 
TABLE 5. REASONS FOR DISCONTINUATION OF ENROLLMENT METHOD, BY ENROLLMENT METHOD

\begin{tabular}{|c|c|c|c|c|c|}
\hline \multirow[b]{2}{*}{ Discontinuation reason ${ }^{\dagger}$} & \multicolumn{4}{|c|}{ Enrollment Method } & \multirow[b]{2}{*}{$\begin{array}{c}\text { Combined } \\
(\mathrm{n}=921)\end{array}$} \\
\hline & $\begin{array}{l}\text { PPIUD } \\
(n=130)\end{array}$ & $\begin{array}{c}\text { IUD } \\
(n=168)\end{array}$ & $\begin{array}{l}\text { Injectable } \\
(n=313)\end{array}$ & $\begin{array}{c}\text { OCP } \\
(n=310)\end{array}$ & \\
\hline \multicolumn{6}{|l|}{ Fertility-related reasons } \\
\hline Wants to become pregnant & 3.8 & 13.1 & 5.4 & 20.3 & 11.6 \\
\hline Husband not living at home & 12.3 & 7.7 & 3.5 & 18.1 & 10.4 \\
\hline Not having sex & 3.1 & 4.8 & 3.8 & 1.3 & 3.0 \\
\hline Infrequent sex & 5.4 & 1.2 & 1.3 & 1.6 & 2.0 \\
\hline Up to god/fatalistic & 1.5 & 1.8 & 1.0 & 0.6 & 1.1 \\
\hline Can't get pregnant & 3.1 & 1.8 & 0.0 & 0.3 & 0.9 \\
\hline Menopausal/hysterectomy & 0.0 & 0.0 & 0.3 & 0.0 & 0.1 \\
\hline \multicolumn{6}{|l|}{ Opposition to use } \\
\hline Husband opposed & 13.1 & 5.4 & 9.6 & 3.2 & 7.2 \\
\hline Mother-in-law opposed & 7.7 & 1.2 & 3.5 & 1.6 & 3.0 \\
\hline Others opposed & 3.8 & 0.0 & 1.0 & 0.3 & 1.0 \\
\hline Religious prohibition & 0.8 & 0.0 & 0.3 & 0.0 & 0.2 \\
\hline \multicolumn{6}{|l|}{ Lack of knowledge } \\
\hline $\begin{array}{c}\text { Lack of knowledge/does not know a } \\
\text { other method }\end{array}$ & 0.0 & 1.8 & 0.3 & 0.3 & 0.5 \\
\hline Knows no source & 0.0 & 0.0 & 0.3 & 0.6 & 0.3 \\
\hline \multicolumn{6}{|l|}{ Method-related reasons } \\
\hline Side effects/health concerns & 33.8 & 28.0 & 24.6 & 17.1 & 24.0 \\
\hline Not menstruated since start of & 46 & 48 & 514 & 26 & 199 \\
\hline Lack of access/too far & 0.0 & $\begin{array}{l}4.0 \\
0.0\end{array}$ & $\begin{array}{r}1.4 \\
5.4\end{array}$ & $\begin{array}{l}2.0 \\
1.3\end{array}$ & 2.3 \\
\hline Costs too much & 0.0 & 0.0 & 1.6 & 0.0 & 0.5 \\
\hline Inconvenient to use & 1.5 & 5.4 & 1.9 & 3.2 & 2.9 \\
\hline \multicolumn{6}{|l|}{ Interferes with body's normal } \\
\hline processes & 3.8 & 3.0 & 6.1 & 2.3 & 3.9 \\
\hline Wanted more effective method & 2.3 & 4.8 & 0.3 & 3.2 & 2.4 \\
\hline Method failure/pregnancy & 0.0 & 1.8 & 1.3 & 3.9 & 2.1 \\
\hline No reason spontaneously mentioned & 36.2 & 32.7 & 13.4 & 23.2 & 23.5 \\
\hline
\end{tabular}

†Multiple responses possible 


\section{Contraceptive use dynamics after 12 months}

Table 6 presents a cross-sectional look at methods used at the 12-month follow-up interview by enrollment method ( $\mathrm{n}=2,441)$. The percentage of women who were using the enrollment method (highlighted in green) was the highest for OCP users (75 percent), followed by interval IUD users (74 percent), and PPIUD users (66 percent). Only 44 percent of injectable users were using the injectable after 12 months.

Across all methods initiated at enrollment, more users switched to a modern method compared to a traditional method. For example, 23 percent of injectable contraceptive users at enrollment switched to a different modern method by the 12-month interview compared to 13 percent who switched to a traditional method (rhythm method, withdrawal, and abstinence; data not shown). Similarly, 16 percent of PPIUD users switched to another modern method by the 12 -month interview while 12 percent switched to a traditional method. Among interval IUD users, 11 percent switched to another modern method and 5 percent to a traditional method, while 8 percent of OCP users switched to modern and 3 percent switched to traditional methods.

PPIUD users at enrollment switched to withdrawal method (9\%), condoms (8\%), OCPs (5\%), and female sterilization (3\%). Interval IUD users at enrollment mainly switched to condoms (4\%), OCPs (3\%), and withdrawal (3\%). Nearly one-quarter of injectable users at enrollment switched to other methods, such as OCPs $(11 \%)$, withdrawal $(10 \%)$, and condoms $(7 \%)$. OCP users at enrollment switched to female sterilization $(3 \%)$, followed by condoms $(2 \%)$ and withdrawal $(2 \%)$.

Compared to other methods initiated at enrollment, injectable users were more likely to discontinue using contraception altogether by the 12-month interview (20\%) while PPIUD users were least likely to discontinue using contraception by 12 -months $(6 \%)$.

Additional analysis of use dynamics revealed that about five percent of OCP users at enrollment discontinued the method at some point in the study and then switched back to OCPs by the 12-month follow-up. 
TABLE 6. CONTRACEPTIVE USE AT 12-MONTH INTERVIEW, BY ENROLLMENT METHOD

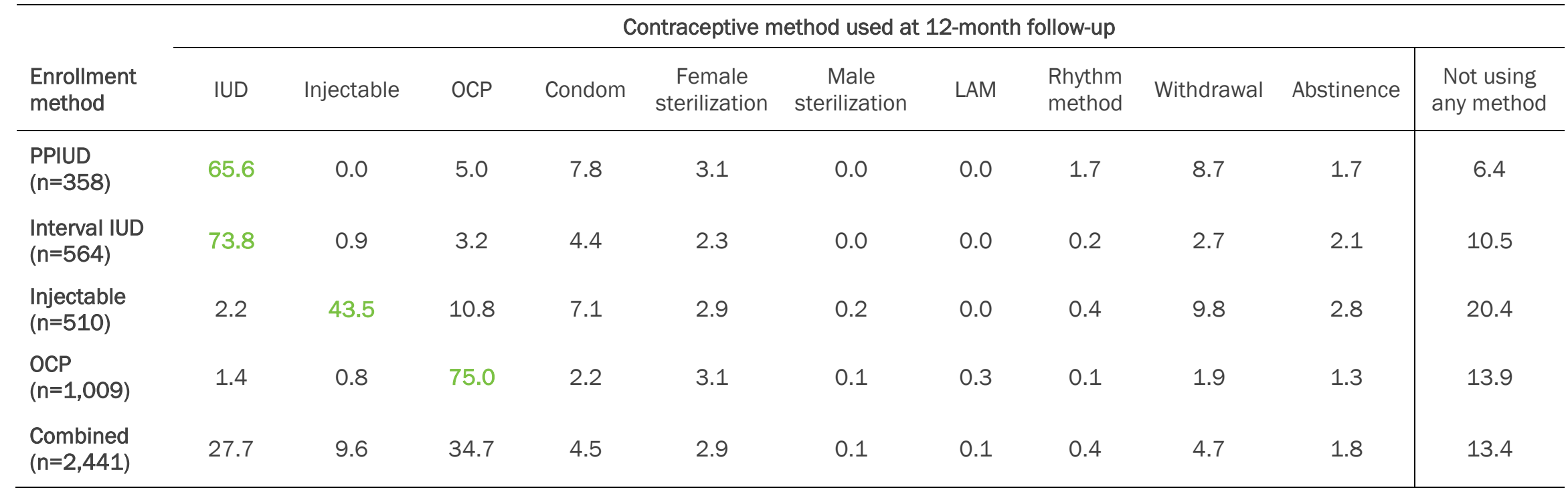


Figure 7 is a Sankey diagram showing how individual women moved through various contraceptive use states over the one-year study period-i.e., at enrollment, and 3, 6, and 12 months later. It includes women who completed at least one follow-up survey $(\mathrm{n}=2,559)$ and excludes 140 women who were lost to follow-up at the 3-month interview and who never returned to the study. The diagram shows the following contraceptive use states of women at each time point: consistent use of the enrollment method (continued enrollment method), use of a different method than the method adopted at enrollment (switched methods), nonuse of any contraceptive method (discontinued contraception), and lost to follow-up. On the left side of the diagram, users of each enrollment method are presented by color, and the colors represent the enrollment method throughout the diagram. For example, women who adopted the PPIUD $(n=376)$ at enrollment are presented in navy blue and can be followed through the study by this color.

The percentages on the figure represent women's contraceptive use states cross-sectionally-that is, the percentage of women at each time point in each state, regardless of their individual movement. At the 3month interview, three-quarters $(75 \%)$ of women were still using their enrollment methods, and this dropped slightly to 69 percent at the 6-month interview. By the 12-month interview, over half of women $(61 \%)$ had consistently used their enrollment method. Cross sectionally, the percentage of women who switched to a different method (including both modern and traditional methods), increased from 8 percent at 3 months to nearly one-quarter $(22 \%)$ at the 12 -month interview. This includes women who switched methods at that follow-up interview regardless of whether they continued to use the same method at subsequent interview(s). By the end of the study period, 22 percent of women had switched to a different method. This included 15 percent who switched to a modern method and 7 percent who switched to a traditional method.

Cross-sectionally, the percentage of women who were not using any contraceptive method at each interview slightly increased from 7 percent at 3 months to 10 percent at 6 months, and to 13 percent at 12 months. Some women who discontinued a contraceptive method by the 3- and 6-month interview returned to FP by a subsequent follow-up interview: $3 \%$ of women discontinued a method at 3 months and began a new episode of use at 6 months, and 3\% of women were not using a method at 6 months but began a new episode of use by 12 months. The 13 percent of women who were not using a method at 12 -months comprised 4 percent who wanted a child within the next two years and 9 percent with an unmet need for family planning (data not shown). ${ }^{2}$

Figure 7 further demonstrates that although 61 percent of women continued to use the enrollment method consistently for one year, there is a considerable amount of movement among states: switching to other FP methods, consistently using the switched methods, or discontinuing contraceptive use altogether. These data suggest that continuous support of women with information and opportunities to switch methods is critical to support women's changing desires for various methods over time. Simply offering and distributing FP methods at one time is not enough to meet women's need for voluntary contraceptive use.

\footnotetext{
${ }^{2}$ Unmet need for family planning includes women who were not using a method but did not want to have any more
} children, wanted to wait more than two years, or did not know whether or when they wanted to have a child. 


\section{FIGURE 7. WOMEN'S MOVEMENT THROUGH VARIOUS CONTRACEPTIVE USE STATES OVER 1-YEAR STUDY PERIOD}

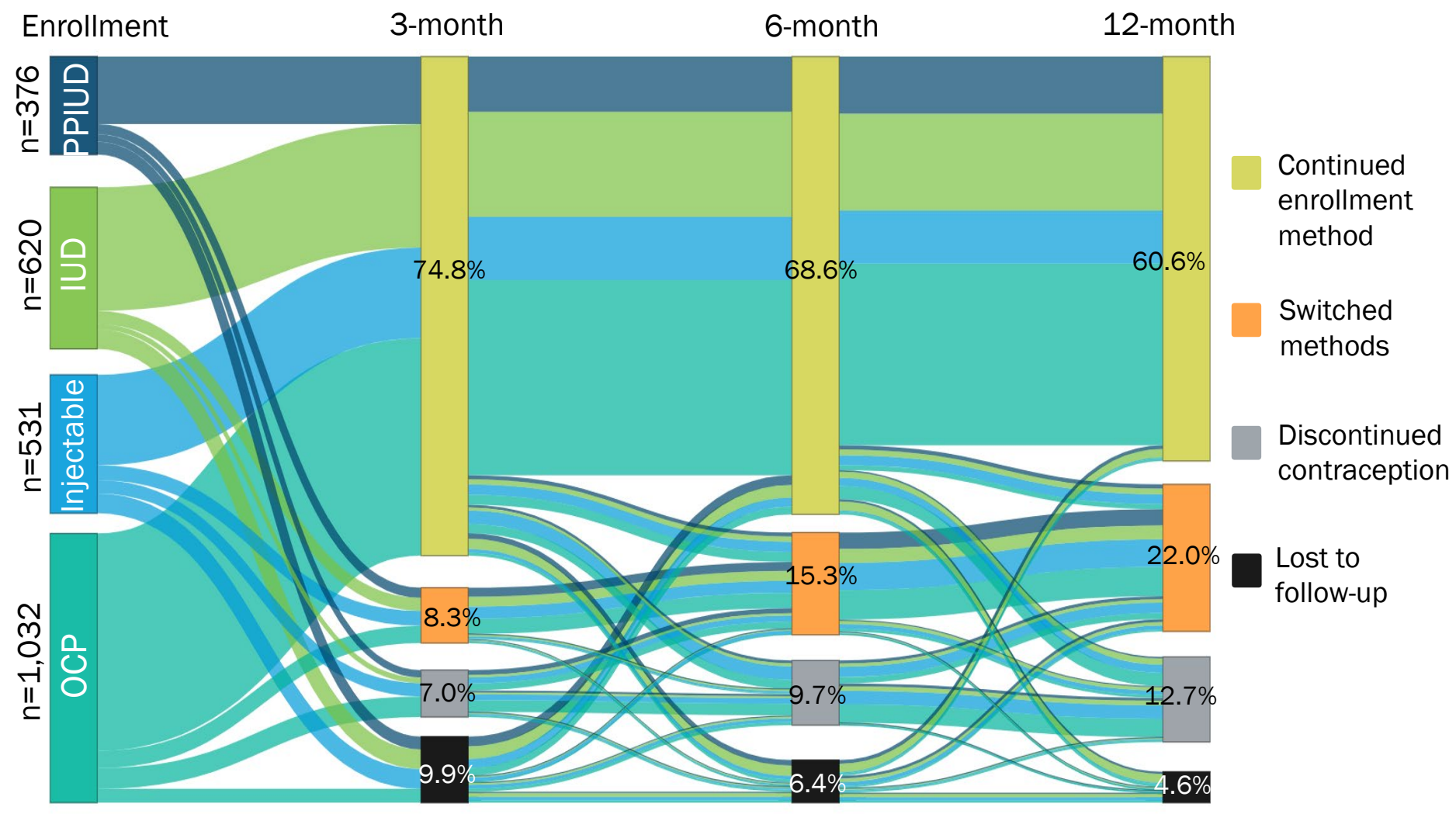




\section{Fertility preferences at 12-month follow-up}

Figure 8 presents three pie charts of fertility preferences reported at the 12-month follow-up interview for: 1) modern method users $(\mathrm{n}=1,945) ; 2)$ traditional method users $(\mathrm{n}=170)$; and 3$)$ non-users of any family planning method ( $\mathrm{n}=326)$. Most women $(64 \%)$ who were using a modern method at the 12 -month interview did not want to have any children in the future. Seventeen percent wanted to wait more than two years to have a child, 3 percent wanted to have a child within one to two years, and one percent wanted to have a child within the next year. Fifteen percent didn't know whether or when they wanted to have their next child.

More than half $(56 \%)$ of traditional method users did not want to have any more children at the time of the 12-month follow-up and 14 percent wanted to wait for two years or more before having their next child. Four percent wanted a child within one to two years and 2 percent wanted to have a child within the next year.

Nearly one-quarter (24\%) didn't know whether or when they wanted to have their next child. Among women who were not using any family planning method, 50 percent did not want to have any more children, 7 percent wanted to wait two years or more, and 12 percent didn't know whether or when they wanted to have a child, suggesting a significant level of unmet need for family planning among this group of non-users. Over one-quarter $(26 \%)$ wanted to have a child within the next year, a much greater proportion than for modern and traditional method users.

Among the 50 percent of non-users who did not want to have any more children $(n=163)$, the main reasons for discontinuing their most recent method were not menstruating since beginning the method (reported by $20 \%$ ), side effects/health concerns (20\%), and husband not living at home (18\%) (data not shown).

\section{FIGURE 8. FERTILITY PREFERENCES AT 12-MONTH FOLLOW-UP AMONG USERS OF MODERN METHODS, TRADITIONAL METHODS, AND THOSE NOT USING ANY METHOD}

\begin{tabular}{|l||l|l|}
\hline $\begin{array}{l}\text { Modern method users } \\
(\mathrm{n}=\mathbf{1}, 945)\end{array}$ & $\begin{array}{c}\text { Non-users } \\
(\mathrm{n}=326)\end{array}$ \\
\hline
\end{tabular}


Figure 9 shows that at the individual-level, fertility preferences change over time and do so within relatively short time intervals. While looking at the data cross-sectionally, it appears that fertility preferences are relatively stable - between 54 and 59 percent of respondents reported not wanting any more children at enrollment. However, when examining preferences at the individual level, preferences can vary substantially over a one-year period. Among the 59 percent of women who reported not wanting any more children at enrollment, 35 percent reported they wanted to have a child in at least one follow-up survey (data not shown). Similarly, while 28 percent of women reported they wanted to wait more than two years before having a child at enrollment, nearly all (95\%) of them changed their preference in a follow-up interview. Among the 6 percent who wanted a child within two years at enrollment, 86 percent changed their preference in at least one follow-up. Lastly, of the 7 percent of women who were not sure whether or when they wanted a child at enrollment, 87 percent changed their response in a follow-up interview. Cross-sectionally, the proportion of women who were unsure whether or when they wanted to have more children doubled by the end of the study, from 7 percent at enrollment to 15 percent at the 12-month interview.

These data suggest that while cross-sectionally fertility intentions appear to be relatively stable over time, when examined at an individual level, fertility preferences fluctuate substantially. In these data, 35 percent of women who had wanted no more children at enrollment changed their fertility preference to wanting a child at some time-point during the year. This suggests that providers should be cautious about how they use this measure in supporting women to choose a contraceptive method, especially when counseling on female sterilization. Understanding the strength of women's motivations to prevent pregnancy could improve providers' counseling and support of appropriate method selection. For example, providers may ask woman the circumstances that would influence her to change her mind about wanting no more children. Other changes in fertility preferences were observed to be in an expected direction where over time women moved from wanting a child in over two years to wanting no more children.

\section{FIGURE 9. INDIVIDUAL WOMEN'S CHANGES IN FERTILITY PREFERENCES OVER 1- YEAR STUDY PERIOD}

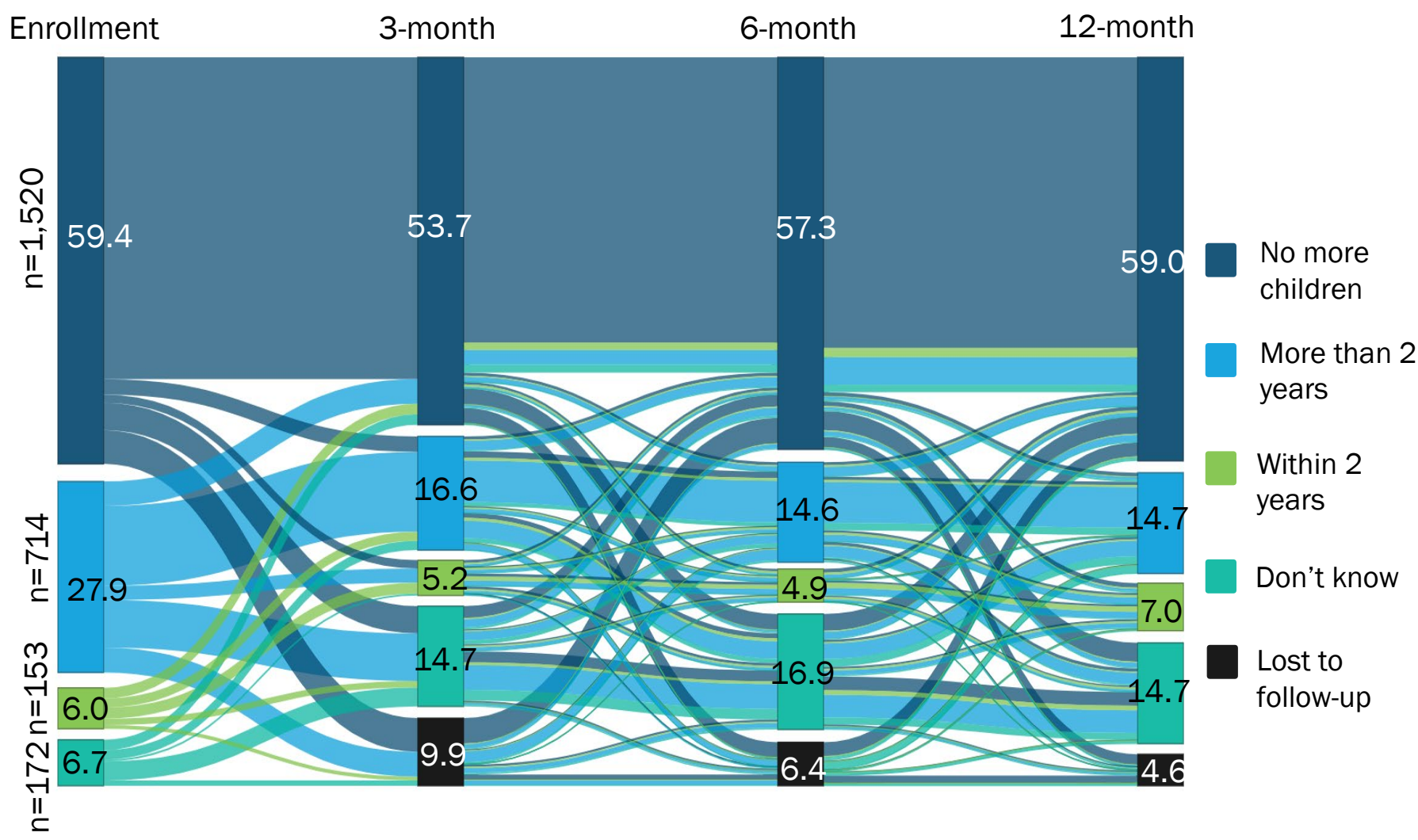


Experiences using and obtaining contraceptive methods at 12 months

\section{Experiences with OCP use}

\section{Source of OCPs}

Women using OCPs at 12-month follow-up $(n=848)$ were asked where they had obtained their most recent packet of pills (Figure 10). The majority (86\%) reported receiving the packet from a frontline health worker, including ASHAs and AWWs. Eight percent purchased a packet from a medical store, 3 percent received it from a government hospital, and 2 percent from a private doctor. Eighty-five percent did not pay anything for their last pill packet, while 7 percent paid between one and 29 rupees, 6 percent paid between 30 and 350 rupees, and 2 percent didn't know (data not shown). Most women who went to private sources paid for their pills, as 74 percent of those who went to a medical store paid for their last packet (and an additional 22 percent didn't know or remember the cost), and 95 percent of those who went to a private doctor paid for their pill packet. Those who obtained their packet from the public sector were less likely to pay: 10 percent of those who went to a government health facility and 4 percent who received it from an ASHA paid for their pill packet (data not shown).

\section{FIGURE 10. SOURCE OF MOST RECENT OCP PACKET AMONG OCP USERS AT 12- MONTH FOLLOW-UP $(\mathrm{N}=848)$}

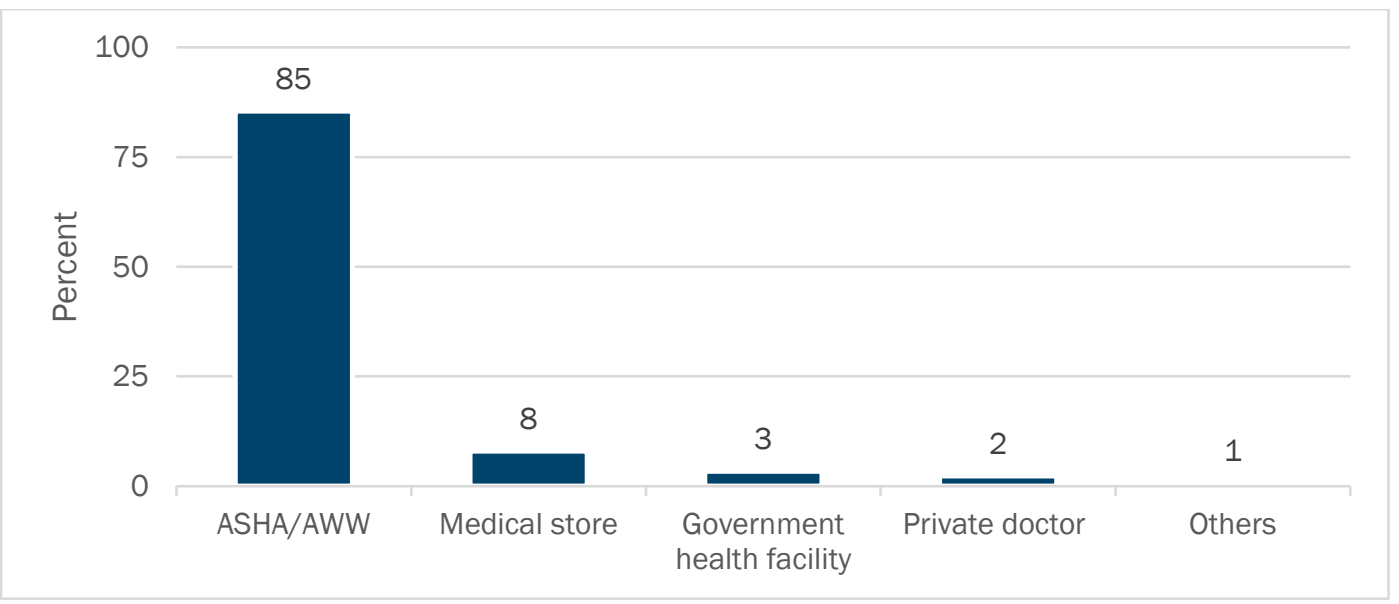




\section{Missed doses of OCPs}

Those using OCPs at 12-months $(\mathrm{n}=848)$ were also asked whether they had missed any doses of the pill. ${ }^{3}$ Seventeen percent of OCP users reported missing a dose in this period (Table 7). Women were also asked what they did when they realized they had missed a dose, the reason they missed a dose, and how many times they had missed a dose. After realizing they had missed the dose, 12 percent of pill users took two pills at once the next day, and 2 percent took the forgotten pill immediately upon remembering, which are the correct reactions to a missed dose, while 3 percent took one pill the next day. Less than one percent discontinued OCPs when they missed a dose. The most common reason reported for missing the dose was forgetting to take the pill, reported by 10 percent of OCP users, while 4 percent forgot their pill packet while traveling, 3 percent ran out of pills, and less than one percent reported other reasons. Of those who had missed a dose, most had missed more than one dose: 8 percent of pill users missed a dose twice and 6 percent missed a dose three or more times.

\section{TABLE 7. AMONG OCP USERS AT 12-MONTHS, THE PERCENTAGE WHO MISSED A DOSE AND THEIR REACTIONS, REASONS, AND NUMBER OF DOSES MISSED $(\mathrm{N}=\mathbf{8 4 8})$}

\begin{tabular}{lcc}
\hline & \multicolumn{2}{c}{ OCP users at 12-month $(\mathrm{n}=848)$} \\
\cline { 2 - 3 } Experiences missing OCP doses & $\%$ & $\mathrm{n}$ \\
\hline Proportion that missed a dose & 17.0 & 144 \\
Reaction to missed dose & 11.6 & 98 \\
$\quad$ Took two pills at once the next day & 2.9 & 25 \\
Took one pill the next day & 2.4 & 20 \\
Took a pill immediately & 0.1 & 1 \\
Discontinued OCP & & 81 \\
Reason the dose was missed & 9.6 & 33 \\
Forgot to take the pill & 3.9 & 29 \\
Forgot pill packet while traveling & 3.4 & 1 \\
Was out of pills & 0.1 & 27 \\
Other & & 65 \\
How many times a dose was missed & 3.2 & 52 \\
Once & 7.7 & \\
Twice & 6.1 & \\
Three or more times & & \\
\hline
\end{tabular}

\section{Consistency of OCP use while husband is away}

Women whose husbands occasionally lived elsewhere for work $(n=265)$ were asked whether they took their doses of OCPs when their husbands were away. Seventy-three percent of these women reported that they took their pills regularly while their husband was away (data not shown).

\section{Experiences with injectable use}

Women using the injectable at the 12-month interview $(n=235)$ were asked where they plan to receive their next dose of the injectable. Just over half $(51 \%)$ said they would go to a government hospital, 46 percent to an NGO-run clinic, and 2 percent to a private doctor.

\footnotetext{
${ }^{3}$ For those who had continued using OCPs since the preceding interview, this question asked about the three months preceding the interview, while new OCP users since the last interview were asked this since beginning the method.
} 
At their previous visit to receive the injectable method, 48 percent of injectable users at 12 months ( $\mathrm{n}=235$ ) did not pay for the injectable method, and 46 percent paid 200 rupees for the injection. One percent paid between 1 and 150 rupees, while 5 percent paid between 300 and 305 rupees (data not shown).

\section{Experiences with IUD use}

\section{IUD follow-up visits}

The World Health Organization (WHO) recommends women go for a follow up 3-6 weeks after insertion, and then at any time to discuss side effects, problems, switching methods, or IUD removal (WHO 2016). Of 676 women using the IUD (both PPIUD and interval IUD) at 12-month follow-up interview, just over half (54\%) reported going for a follow-up visit after receiving the IUD and most of them (53\%) went to the same public facility where they had the IUD inserted (Table 8). Of all IUD users, 6 percent went to a follow-up visit unaccompanied. Twenty-two percent were accompanied by their husband, 22 percent went with an ASHA, and 2 percent were accompanied by their mother-in-law. Others went to the follow-up visit with their mother, sister, or someone else. Just over one-quarter (27\%) of IUD users went to see if everything was all right, 20 percent reported that the provider asked them to return, 7 percent went to the facility for child immunization, and one percent went to consult their provider about side effects.

TABLE 8. PROPORTION OF IUD USERS WHO WENT FOR IUD FOLLOW-UP VISIT, LOCATION OF VISIT, AND PERSON ACCOMPANIED TO VISIT AMONG IUD USERS AT 12-MONTH INTERVIEW ( $\mathrm{N}=676)$

\begin{tabular}{lcc}
\hline & & \\
\cline { 2 - 3 } IUD follow-up visits & $\%$ & $\mathrm{n}$ \\
\cline { 2 - 3 } & 54.3 & 367 \\
\hline Proportion that went for follow-up visit & \\
Location of follow-up visit & & 358 \\
The same facility as insertion & 53.0 & 8 \\
A different government facility & 1.2 & 1 \\
A different private facility & 0.1 & 151 \\
Person who accompanied IUD user to visit & & 149 \\
Husband & 22.3 & 12 \\
ASHA & 22.0 & 5 \\
Mother-in-law & 1.8 & 4 \\
Sister-in-law & 0.7 & 3 \\
Mother & 0.6 & 2 \\
Sister & 0.4 & 41 \\
Other family member or neighbor & 0.3 & \\
No one & 6.1 & 179 \\
Reason for follow-up visit & & 135 \\
Just wanted to see if everything was all right & 26.5 & 46 \\
Provider asked respondent to return for follow-up & 20.0 & 7 \\
Went for child immunization & 6.8 & \\
Consult on side effects & 1.0 & \\
\hline
\end{tabular}

Forty-six percent of IUD users did not go for a follow-up visit after receiving the IUD. Forty-three percent of IUD users at 12 months said they did not go for a follow-up visit because they did not have any problems with their IUD. One percent did not have anyone to accompany them to the facility. Other reasons named by less than one percent of IUD users included not having money to go for a follow-up visit, having personal or family problems, or feeling afraid to go for a follow-up (data not shown). 


\section{IUD removal}

At 12-month follow-up interview, 13 percent of 775 IUD users discontinued using the IUD since the previous interview. Three percent of IUD users went to the same facility where the IUD was inserted to have it removed, 4 percent reported going to a different facility from where their IUD was inserted, and 3 percent reported the IUD was expelled on its own (data not shown).

\section{Experiences with female sterilization}

By the 12-month interview, 41 women had transitioned to female sterilization, including 3 percent of those using PPIUD at enrollment, 2 percent of interval IUD users, 3 percent of injectable users, and 3 percent of OCP users. Table 9 provides information about their experiences when undergoing sterilization. Forty-four percent of women reported their sterilization took place in a government hospital; 27 percent in a community health center, rural hospital, or primary health center; 15 percent went to a government dispensary; and 7 percent went to an NGO or trust hospital.

Sterilization users also reported on the care they received at the time of sterilization. Ninety-five percent said they were told they would not be able to have any more children before the procedure. Slightly less than half $(46 \%)$ reported that the care they received during sterilization was "very good," 51 percent reported it was "all right," and one woman reported it was "not so good." When asked if they regret having the sterilization, all women responded that they did not regret having the procedure.

\section{TABLE 9. DETAILS OF FEMALE STERILIZATION ADOPTION BY 12-MONTH FOLLOW- UP INTERVIEW ( $N=41)$}

\begin{tabular}{|c|c|c|}
\hline & \multicolumn{2}{|c|}{$\begin{array}{l}\text { Sterilization users at 12-month } \\
\qquad(n=41)\end{array}$} \\
\hline & $\%$ & $\mathrm{n}$ \\
\hline \multicolumn{3}{|l|}{ Location of sterilization } \\
\hline Government hospital & 43.9 & 18 \\
\hline $\mathrm{CHC} /$ rural hospital/PHC & 26.8 & 11 \\
\hline Government dispensary & 14.6 & 6 \\
\hline NGO or trust hospital/clinic & 7.3 & 3 \\
\hline Private hospital & 2.4 & 1 \\
\hline Other & 4.9 & 2 \\
\hline \multicolumn{3}{|c|}{ Respondent was told she would not be able to have additional children } \\
\hline Yes & 95.1 & 39 \\
\hline No & 4.9 & 2 \\
\hline \multicolumn{3}{|c|}{ Respondent's rating of care received during procedure } \\
\hline Very good & 46.3 & 19 \\
\hline All right & 51.2 & 21 \\
\hline Not so good & 2.4 & 1 \\
\hline \multicolumn{3}{|c|}{ Respondent regrets having female sterilization } \\
\hline No & 100 & 41 \\
\hline
\end{tabular}




\section{Experiences of pregnancy during 12-month study period}

At each follow-up interview, women were asked whether they had experienced a pregnancy in the preceding three months. Table 10 presents the proportion of women who reported experiencing a pregnancy at some point during the study, among all women who were interviewed in at least one follow-up interview ( $\mathrm{n}=2,559)$. These proportions are not contraceptive failure rates, as some women had stopped using their contraceptive method prior to experiencing pregnancy. Overall, 7 percent reported experiencing a pregnancy during the study. Ten percent of OCP users, 8 percent of injectable users, 5 percent of interval IUD users, and 2 percent of PPIUD users at enrollment experienced a pregnancy.

\section{TABLE 10. EXPERIENCE OF PREGNANCY DURING THE 12-MONTH STUDY PERIOD, BY ENROLLMENT METHOD}

\begin{tabular}{lcc}
\hline & \multicolumn{2}{c}{ Experienced a pregnancy at some point during the study } \\
\cline { 2 - 3 } Enrollment method & $\%$ & $\mathrm{n}$ \\
\hline PPIUD $(\mathrm{n}=376)$ & 2.4 & 9 \\
Interval IUD $(n=620)$ & 5.6 & 35 \\
Injectable $(n=531)$ & 7.7 & 41 \\
OCP $(n=1,032)$ & 9.5 & 98 \\
Combined $(n=2,559)$ & 7.2 & 183 \\
\hline
\end{tabular}

$* \mathrm{p}<0.05$

Clients who experienced a pregnancy during the study period $(n=183)$ were also asked about the intendedness of that pregnancy: whether the pregnancy was wanted then, wanted later, or not wanted at all (Table 11). Intendedness of the pregnancy was asked of women when the pregnancy was first reported. Slightly less than half $(49 \%)$ of women who experienced a pregnancy wanted their pregnancy at the time they became pregnant, while 24 percent wanted to become pregnant at a later time. Just over one-quarter $(27 \%)$ did not want to become pregnant at all, and one percent didn't know.

TABLE 11. INTENDEDNESS OF PREGNANCY WHEN FIRST REPORTED, AMONG WOMEN WHO EXPERIENCED A PREGNANCY DURING THE STUDY PERIOD, BY ENROLLMENT METHOD

\begin{tabular}{lcccc}
\hline & \multicolumn{4}{c}{ Intendedness of pregnancy when first reported } \\
\cline { 2 - 5 } Enrollment method & Wanted then & Wanted later & Not wanted at all & Don't know \\
\hline PPIUD $(n=9)$ & 66.7 & 11.1 & 22.2 & 0.0 \\
IUD $(n=35)$ & 60.0 & 17.1 & 22.9 & 0.0 \\
Injectable $(n=41)$ & 34.1 & 19.5 & 43.9 & 2.4 \\
OCP $(n=98)$ & 50.0 & 28.6 & 20.4 & 1.0 \\
Combined $(n=183)$ & 49.2 & 23.5 & 26.2 & 1.1 \\
\hline
\end{tabular}

Of those who reported wanting their pregnancy at the time they became pregnant, 64 percent reported that they had discontinued their enrollment method due to a desire to become pregnant, while others discontinued due to side effects (11\%), lack of menstruation $(6 \%)$, inconvenience $(2 \%)$, husband not living at home $(2 \%)$, husband opposition (1\%), mother-in-law opposition $(1 \%)$, or did not list a reason $(18 \%)$ (multiple responses possible, data not shown). On the other hand, 23 percent of those who wanted their pregnancy later and 17 percent of those who did not want their pregnancy at all reported discontinuing their 
enrollment method due to method failure. However, 37 percent of those who reported they wanted their pregnancy at a later time also reported that they discontinued because they wanted to become pregnant, while this was a reason for only 7 percent of those who reported they did not want to become pregnant at all. Side

effects/health concerns was a reason for discontinuation listed by 10 percent of those who wanted to become pregnant later and 24 percent of those who did not want to become pregnant at all, suggesting that these women would have been potential candidates for method switching.

Women who reported experiencing a pregnancy during the study also reported whether that pregnancy ended in termination or miscarriage. Of the 183 pregnancies reported during the study period, six ended in miscarriage and 25 ended in termination. Eight women used a pill to terminate the pregnancy, while 17 reported termination by a cleaning done by a doctor or nurse (data not shown).

\section{Strengths and limitations of the study}

This study has collected longitudinal data on modern reversible contraceptive users in India, a largely understudied group, but a group that is a focus of India's FP2020 commitment. One of the most significant strengths of this study was that it was conducted prospectively, so that the effect of recall bias on responses was reduced considerably compared to retrospective studies.

One limitation of the study is that timing and strategies for enrollment into the study varied by state and family planning method. Women in Haryana were enrolled into the study via ASHAs and enrollment began several months after it began in Odisha, where enrollment occurred at government facilities, at NGO facilities, and through ASHAs.

Additionally, enrollment of injectable users was challenging, and the desired sample size was not met, as the study began just before the method was rolled out in the public sector. However, these findings can be useful for the Government of India in planning how to allocate future resources for injectable use. 


\section{Discussion}

The purpose of this longitudinal study was to assess the dynamics of reversible contraceptive use over the course of one year, including contraceptive choice, discontinuation, and switching behaviors, as well as quality of care and experience of side effects. A total of 2,699 married women of reproductive age (15-49 years) from Odisha and Haryana states were enrolled into the study, including 420 PPIUD users, 640 interval IUD users, 581 injectable users, and 1,066 OCP users. As respondents were purposively sampled, estimates are not representative of contraceptive users at the state level nor of all method-specific users. However, these data can provide valuable insights for understanding the experiences of reversible contraceptive users, which is critical in India as the government aims to expand access to and use of reversible contraceptives in its national family planning program.

In the enrollment interview, women were asked about the quality of care they received from the provider or frontline health worker who provided them with or counseled them about their method. While there were some aspects of quality of care that the majority of women across all methods received, such as being treated well $(99-100 \%)$ or being told how the chosen method works (ranging from 66 percent of PPIUD users to 91 percent of OCP users), there is room for improvement in quality, because 100 percent of women should be reporting receiving quality of care across the four domains: respectful care, method selection, effective use of method selected, and continuity of contraceptive use and care. Though this study did not observe clientprovider interactions, clients' reported quality received provides insights into what information they were walking away with after interacting with providers. Additionally, while responses about process quality received may be subject to recall bias, this is likely to be minimal because the enrollment interview occurred within 30 days of a woman receiving her family planning method.

There were differences in quality received by method and other respondent characteristics. For instance, PPIUD users consistently reported receiving lower levels of quality of care compared to users of other methods. PPIUD users may have received counseling and information from providers or frontline health workers during antenatal care visits, but the information exchange between provider and client should be reiterated at the time of insertion, even if counseling had occurred prior. Additionally, the differences in receipt of the MIIplus by wealth tertile and urban/rural residence suggest that there is a need to ensure that all women receive high quality care, regardless of their financial means and where they live.

Implications: Quality of care should be improved for users of all modern methods of family planning, and especially for PPIUD users and women of lower wealth status. Quality of care improvement efforts should also be routinely monitored and tracked to ensure that women are receiving high quality services. Providers of all cadres should be trained on respectful care, and information exchange on appropriate method selection, effective use of methods, and continuity of contraceptive use and care.

At each follow-up interview, women were asked whether they had experienced side effects of their family planning method. Just 23 percent of women had experienced at least one side effect while using their enrollment method throughout the course of the study, though this varied widely by method. Half of injectable users $(50 \%)$ experienced a side effect while using the method, while this was true for 22 percent of PPIUD users, 22 percent of IUD users, and 11 percent of OCP users. The most common side effects were heavy bleeding (reported by $6 \%$ of women), abdominal pain (6\%), and lack of menstruation $(6 \%)$. Less than one in five women $(18 \%)$ talked to someone about side effects, and only 12 percent spoke to a provider or health worker about the side effects, suggesting women who have recently begun using a contraceptive 
method are not always seeking follow-up care or being visited by frontline health workers. Injectable users were the most likely to experience side effects, and also the most likely to discontinue their method over the course of the study. As the injectable is a relatively new method available in public health facilities in India, understanding that half of injectable users experienced side effects and most discontinued the method is valuable information for the Indian government to use in efforts to make the method more widely available across the country. Before starting the method, women who receive the injectable should be adequately counseled on side effects of the method, what to do if they experience side effects, and what methods they could switch to if the side effects of the injectable make it an unsuitable method.

Women's reasons for discontinuation of the enrollment method shed additional light on their contraceptive use dynamics. Among women who discontinued the enrollment method at some point during the study ( $\mathrm{n}=921$ ), reasons for discontinuation were primarily related to the method used: the most commonly cited reason was side effects/health concerns (24\%). Twenty percent discontinued due to not menstruating since starting the method, and this was the most common reason among injectable users. Given this large proportion of discontinuation due to side effects and changes in menstruation, it is critical that providers discuss potential side effects of available methods, how they might impact women's lives, and any other health concerns a woman has before she adopts a method. Modern fertility-awareness based methods may be a suitable alternative for women who want to prevent pregnancy but find these side effects unacceptable, and should be included in counseling on method selection. Other women discontinued for fertility-related reasons: 12 percent of discontinuers wanted to become pregnant and 10 percent reported their husband was not living at home, and these proportions were greater among OCP users. These women did not have an immediate need for family planning and discontinued their method according to their fertility preferences and needs.

Implications: Most women (77\%) did not report experiencing side effects on their enrollment method, though many who discontinued the enrollment method did so due to side effects or other health concerns. Contraceptive initiators should receive follow-up visits from frontline health workers to provide support and answer questions related to the method selected. These visits could assist women with information on managing side effects or switching to a different method.

While most women - 61 percent — continued to use the method they adopted at enrollment throughout the year, considerable movement among contraceptive use states was observed, including switching to different FP methods, continuing use of the switched methods, or discontinuing contraceptive use altogether. These findings highlight the importance of providers and ASHAs offering continuous support to women who want to delay or prevent pregnancy that includes opportunities to switch methods as their fertility desires change over time. Information and FP methods offered to women at the initial FP visit alone is not enough to ensure that women continuously meet their needs for voluntary contraceptive use; continuous follow-up is needed.

Interval IUD (74\%) and OCP $(75 \%)$ users were most likely to continue to use these methods they began at enrollment, followed by PPIUD users (66\%). Less than half (44\%) of injectable users continued to use injectables. While many of those who initiated the injectable at enrollment went on to switch to a different modern method by 12 months $(23 \%)$, one-third (33\%) discontinued modern contraception altogether. Compared to other methods, injectable users tended to be older in age, had more living children, were more likely to have used a modern method previously, and were more likely to want to stop childbearing all together at enrollment. Sixty-eight percent of those who initiated injectables at enrollment, but discontinued contraception altogether did not want to have any more children at 12 months, suggesting that these injectable discontinuers are potential good candidates for receiving information and support to switch to a different modern method. 
The importance of ensuring women are provided with information about contraceptive switching is underlined by the high level of unmet need among women who discontinued using contraception after one year. Overall, discontinuation of all contraception was low, at 13 percent. However, less than one-third of those not using any method after one year wanted to get pregnant in the next two years $(31 \%)$. Half of those not using any method did not want to have any more children in the future, 7 percent wanted to wait more than two years, and 12 percent didn't know. These women, a total of 69 percent of non-users, therefore had an unmet need for contraception at the end of one year and may benefit from information and support to enable switching to a different modern method of contraception.

Implications: Discontinuation of contraceptive use altogether after one year was relatively low. There was considerable movement between various states of contraceptive use. Women did switch to other methods, both modern as well as traditional methods. Among those who were not using at 12 months, however, the majority had an unmet need for family planning. At the time of method adoption and after the initial visit, it is important to continue to offer women information about the possibility of switching to other methods, including modern fertility awareness-based methods.

At enrollment, most women wanted to use their family planning method for limiting (59\%) or delaying childbearing for at least two years (28\%). While these preferences appeared to be relatively stable over time, there were substantial variations in fertility preferences over the course of the study at the individual level. For example, when examining the data longitudinally, over one-third $(35 \%)$ of women who did not want to have any children at enrollment changed their mind and reported wanting to have more children in at least one follow-up interview. This was even higher for women who reported wanting a child within two years $(86 \%$ changed their mind), in more than two years (95\% changed their mind), or didn't know (87\% changed their mind). Additionally, a significant proportion didn't know whether or when they wanted to have another child in at least one interview, as 6 percent of respondents at enrollment and 15 percent after one year were unsure. Being unsure of fertility preferences is a legitimate response that may change over time, and providers and ASHAs should be sure to ask women about their fertility preferences at each interaction.

When asking women about their fertility desires, a better understanding of their motivations to prevent pregnancy and under what circumstances they may change their mind may help providers support women in selecting appropriate methods. Particularly in India, where 75 percent of family planning users use female sterilization, a deeper understanding of fertility desires and motivations may help to prevent sterilization regret, which has been reported by seven percent of women who have undergone the procedure (Singh 2018).

Implications: These data show that while fertility intentions appear to remain relatively consistent over a year, women's desires can and do change. Asking women about their fertility intentions and motivation to prevent pregnancy routinely in FP counseling can help ensure that women are selecting methods that best meet their changing reproductive needs.

After one year, 62 percent of respondents did not want to have any more children. While those using modern methods after one year were most likely to report not wanting to have any more children (64\%), over half of those using traditional methods (56\%) and half of those not using any method (50\%) did not want any more children either. Women using traditional methods or not using family planning at all would be potential candidates for modern methods of contraception, including modern fertility awareness-based methods, and should be supported in switching to a different modern method if that would better meet their contraceptive needs. Since such a large proportion of modern, traditional, and non-users of family planning desired no more children, and since this was the strongest fertility preference among this sample of women, there is a 
rationale to continue supporting the female sterilization program in India. Coupled with counseling about fertility preferences and motivation to prevent pregnancy, this could help enable women in India with an unmet need for limiting to meet their reproductive intentions.

Implications: India should continue to expand the basket of methods available to women while supporting sterilization as part of the national family planning program.

Seven percent of women, including both those who were using and not using a method the time of followup, experienced a pregnancy at some point during the study. (This study did not calculate failure rates of contraceptive methods.) Of the 183 women who experienced a pregnancy during the study period, half (51\%) did not want to become pregnant at all, did not want to become pregnant at that time, or didn't know. This underscores the importance of enabling women to continue using modern contraception that fits their reproductive needs. Less than 10 percent of women who experienced a pregnancy terminated the pregnancy.

Implications: As half of pregnancies experienced in this study were not wanted at all or at that time, there is a need to ensure that women are offered an array of methods to switch to in order to prevent unwanted pregnancies. 


\section{References}

Family Planning 2020 and Government of India. 2017. Family Planning 2020 Commitment. London, UK.

International Institute for Population Sciences (IIPS). 1995. National Family Health Survey (MCH and Family Planning), India 1992-93. Bombay: IIPS.

International Institute for Population Sciences (IIPS) and ICF. 2017. National Family Health Survey (NFHS4), 2015-16. Mumbai, India: IIPS.

Jain, Anrudh K., John Townsend, and Saumya RamaRao. 2018. Proposed metrics to measure quality: An overview. Working Paper no. 3, prepared for the Measuring and Monitoring Quality of Care Project. New York: Population Council.

Jain, Aparna, Kumudha Aruldas, Arupendra Mozumdar, Elizabeth Tobey, and Rajib Acharya. 2019a.

Validation of Two Quality of Care Measures: Results from a Longitudinal Study of Reversible Contraceptive Users in India. Studies in Family Planning, 50(2): 179-193.

Jain, Aparna, Kumudha Aruldas, Elizabeth Tobey, Arupendra Mozumdar, and Rajib Acharya. 2019b. Adding a question about method switching to the Method Information Index is a better predictor of contraceptive continuation. Global Health Science and Practice, 7(2): 289-299.

Scott, Kerry, Dena Javadi, and Jessica Gergen. 2014. India's Auxiliary Nurse-Midwife, Anganwadi Worker, Accredited Social Health Activist, Multipurpose Worker, and Lady Health Visitor Programs. Boston, Massachusetts: Initiatives, Inc., CHW Central.

Singh, Abhishek. 2018. Sterilization Regret Among Married Women in India: Trends, Patterns and Correlates. International Perspectives on Sexual and Reproductive Health, 44(4): 167-176.

World Health Organization (WHO). 2016. Selected practice recommendations for contraceptive use: Third edition 2016. Geneva: WHO. 


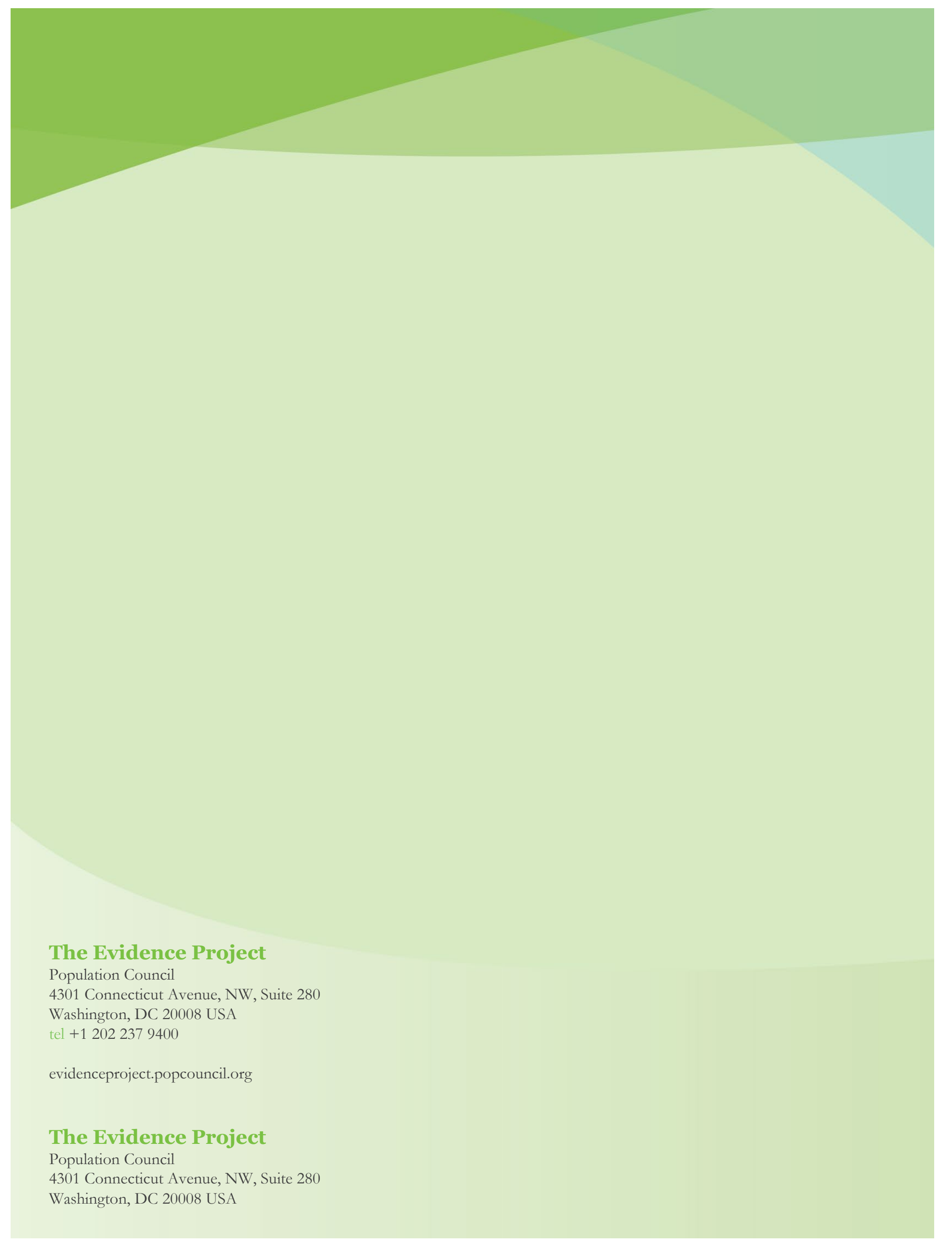

